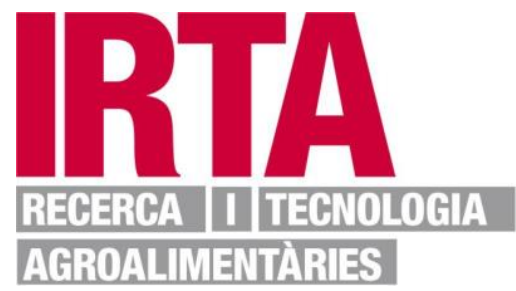

This document is a postprint version of an article published in Food Research International@ Elsevier after peer review. To access the final edited and published work see https://doi.org/10.1016/j.foodres.2020.109025

Document downloaded from:

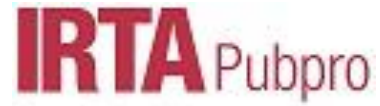

Open dgital archive 


\title{
Emerging Thermal Imaging Techniques for Seed Quality Evaluation: Principles and Applications
}

\author{
Gamal ElMasry ${ }^{1,2,3}$, Ramadan ElGamal ${ }^{2}$ ， Nasser Mandour ${ }^{2}$, Pere Gou ${ }^{1}$, \\ Salim Al-Rejaie ${ }^{3}$, Etienne Belin ${ }^{4}$, David Rousseau ${ }^{4}$ \\ ${ }^{I}$ Institute of Agriculture and Food Research and Technology (IRTA), Finca Camps i Armet s/n, 17121, Monells, \\ Spain (Corresponding author: Tel. +34 666293308, Fax: +34 972630980, Email: gamal.masry@irta.cat) \\ ${ }^{2}$ Agricultural Engineering Department, Faculty of Agriculture, Suez Canal University, Ismailia, Egypt \\ ${ }^{3}$ Department of Pharmacology \& Toxicology, College of Pharmacy, King Saud University, Saudi Arabia \\ ${ }^{4}$ Laboratoire Angevin de Recherche en Ingénierie des Systèmes (LARIS), Université d'Angers, France
}

\begin{abstract}
Due to the massive progress occurred in the past few decades in imaging, electronics and computer science, infrared thermal imaging technique has witnessed numerous technological advancement and smart applications in non-destructive testing and quality monitoring of different agro-food produces. Thermal imaging offers a potential non-contact imaging modality for the determination of various quality traits based on the infrared radiation emitted from target foods. The technique has been moved from just an exploration method in engineering and astronomy into an effective tool in many fields for forming unambiguous images called thermograms eventuated from the temperature and thermal properties of the target objects. It depends principally on converting the invisible infrared radiation emitted by the objects into visible two-dimensional temperature data without making a direct contact with the examined objects. This method has been widely used for different applications in agriculture and food science and technology with special applications in seed quality assessment. This article provides an overview of thermal imaging theory, briefly describes the fundamentals of the system and explores the recent advances and research works conducted in quality evaluation of different sorts of seeds. The article comprehensively reviewed research efforts of using thermal imaging systems in seed applications including estimation of seed viability, detection of fungal growth and insect infections, detection of seed damage and impurities, seed classification and variety identification.
\end{abstract}

Keywords: thermal imaging, thermography, seed, grain, quality, temperature

\section{Introduction}

As the main input for plant and crop production, seeds have an immense biological and economic importance and usually receive great concerns from farmers, producers and seed testing stations to guarantee high quality. Due to growing concerns about food production and enhancing the overall quality of agricultural products, extensive research works have been focused into seed quality 
evaluation (Kim, Kim, Ahn, Yoo \& Cho, 2013). As a result, ensuring seed quality is the priority of modern seed science and a prerequisite for obtaining high yields (Milošević, Vujaković \& Karagić, 2010). This importance of seed and grain quality issues comes from the fact that grains are basically used by humans as foods either by direct consumption or after manufacturing to flour, starch, oil or some other edible products. Seeds could be naked seeds coming from gymnosperms plants or enclosed in a protective structure called the fruit coming from angiosperms plants.

Although seeds are different in shapes, sizes, color, hardness and smoothness, the seed consists fundamentally of embryo, endosperm, and testa. The embryo will eventually grow into a new plant after germination using the nutrients reserved in the endosperm while the testa is a tough outer layer/coat that protects the embryo and endosperm from any possible damages. The food reserves (protein, starch and lipids) in endosperms make many cereals and legumes the major food sources for a large proportion of the world's population. Thus, all stakeholders involved in agricultural production chains such as farmers, traders, distributers and variety registration centers look to the seed quality as a critical component of high production of the all crops. By the way, the term of seed quality differs from the point of view of the people involved in the agricultural production systems but the term itself may generally include purity, uniformity, germinability, vigor, viability, seed health and freedom from physiological disorder, insect infestation or any other deterioration symptoms (Rahman \& Cho, 2016). Being used in the subsequent growing seasons, seeds should go through several testing processes to identify the physicochemical, phytopathological and biological markers that most related to the overall quality and performance (Dell'Aquila, 2007).

As the quality of seeds is strongly linked to the crop yield, productivity and optimization of the cost of crop establishment (Kim \& Lee, 2004), the national seed testing stations and inspection centers tend to adopt the most consistent testing tools that provide reliable measurements of seed quality parameters followed by field inspection, testing and certification. However, some of these measurements such as viability, vigor, internal infestation and seed health are very difficult to obtain directly because it requires prolonged working time and special technical arrangements. The traditional methods used in the determination of the essential seed quality parameters are customarily performed using destructive techniques based on biochemical and molecular methods carried out by experienced seed analysts. Although these lab-based methods are quite effective and accurate, they are suffering from some limitations, as they are inherently destructive, time-consuming and laborious. Hence, the development of non-contact and faster methods with minimum human interposition is critically required to pledge seeds of the highest quality for production and trading purposes (Tsakanikas, Pavlidis \& Nychas, 2015). To keep abreast of modern technological developments in seed testing, the Association of Official Seed Analysts (AOSA) and the International Seed Testing Association (ISTA) realize the importance of developing new advanced technologies to overcome the limitations of the traditional methods of seed quality determination (Boelt, Shrestha, Salimi, Jørgensen, Nicolaisen \& Carstensen, 2018). The need 
of the seed industry sectors to develop such new methods that allow faster assessment of seed quality and composition fostered the research on rapid and non-destructive methods especially the optical ones. The optical, spectral and imaging techniques represent good alternatives of such traditional methods. The measurement of optical properties of seeds has been used successfully for simultaneous determination of several quality traits and for automatic inspection and safety evaluation (ElMasry et al., 2019b). Depending on the type of sensors, acquisition mode and the mathematical chemometrics models used in the analysis, spectral techniques relies on the analysis of light after being reflected, absorbed or transmitted from the examined seeds. Imaging techniques such as spectral imaging, X-ray imaging, thermal imaging, fluorescence imaging, and magnetic resonance imaging provide great capabilities of demonstrating the essential quality attributes (Belin et al., 2018). For instance, X-ray imaging and magnetic resonance imaging techniques are used when the internal anatomical details of the examined seeds are required to estimate seed maturity, internal structure, germination capacity, dormancy, viability, vigor, insect infestation and internal damages in embryo and endosperm (Dell'Aquila, 2004). Meanwhile, spectral imaging and fluorescence imaging techniques are used to know information about the major composition of the seeds (Belin et al., 2018). In seed industry, establishment of imaging techniques can solve many ill-posed issues related to quality assessment and authentication tasks. In addition to the ability of providing information about the physical features and overall quality of the whole seed lot, the computer-integrated imaging techniques can be used to evaluate seeds in individual basis and provide relevant information about their characteristics and quality features.

More recently, the availability of inexpensive imaging devices and the augmented computational power of modern computers have enticed more interests in applying imaging techniques in different agricultural and seed sectors (ElMasry, Mandour, Al-Rejaie, Belin \& Rousseau, 2019a). Due to the rapidity of imaging methods, as well as their accuracy and non-invasiveness, stakeholders involved in seed quality assessment are expecting these innovative methods to improve the efficiency of the seed quality processes. Thus, automation of seed quality assessment is very important during testing and inspection processes and avoid human subjectivity and inconsistency (ElMasry, Kamruzzaman, Sun \& Allen, 2012). While the traditional color imaging provides information about color, shape, size, dimensions, surface structure and texture of the seeds without providing any information about internal features or the composition of these seeds (Tsakanikas et al., 2015), traditional spectroscopy records the spectral signatures of the seeds with virtually no spatial information. Hence, spectral imaging in the form of multispectral imaging or hyperspectral imaging was emerged as a combination of spectroscopy and techniques imaging to provide simultaneous spatial and spectral information about the seeds being analyzed. The later technique has been employed in different applications such as infestation detection, variety identification, seed classification, determination of viability and germination capacity and prediction of chemical composition of different sorts of seed varieties (ElMasry et al., 2019b; Huang, 
Wang, Zhu, Qin \& Huang, 2015; Panagou, Papadopoulou, Carstensen \& Nychas, 2014; Zhang, Liu, He $\& \mathrm{Li}, 2012$ ). As this review article will shed some light on the thermal imaging technique only, all detailed information about the principles, configuration, acquisition modes and applications of other imaging techniques could be found in other sources (ElMasry et al., 2019a; Rahman et al., 2016).

While spectral imaging is used to build a visualized form of an object after being illuminated with rays of light in different visible and invisible regions of the electromagnetic spectrum, thermal imaging technique is a procedure to record the infrared radiation emitted by an object using infrared detectors without the need of illumination source. As the infrared radiation emitted from the object depends principally on its temperature, this thermal information is converted into two-dimensional thermal pictures to demonstrate temperature gradient in the surface of this object without touching it. Contrary to the classic methods of temperature measurements using thermometers, thermocouples or thermistors that can only measure the temperature at a specific spot, the thermal imaging system provide temperature records for all spots in the whole examined objects without a direct contact with the objects being tested. This method has proved applications not only in the quantification of temperature changes on the surface of the objects (Ishimwe, Abutaleb \& Ahmed, 2014), but also for uncovering internal heat intrusions and fluctuation of the thermal properties within objects. Hence, thermal imaging is a noncontact procedure to build a noticeable picture called a thermogram or thermal picture formulated by converting the invisible radiation emitted from target objects into visible temperature records.

Despite the working principles and configurations, there are some similarities and dissimilarities between the thermal imaging and the ordinary imaging systems. The common feature shared between thermal imaging and the other imaging systems is that it is a non-invasive, non-contact and rapid technique. Similar to the other imaging techniques, the infrared thermography can be used for nondamaging monitoring of many quality parameters in different biomaterials like seeds (Chaerle, De Boever, Montagu \& Straeten, 2001; Chaerle, Van Caeneghem, Messens, Lambers, Van Montagu \& Van Der Straeten, 1999). On the other hand, unlike other imaging systems, thermal imaging does not require an illumination source which facilitates applications that the conventional illumination-based imaging systems are unable to offer. More importantly, thermal cameras used in building imaging systems are easy to handle, accurate and adaptable for temperature measurements under different environmental working conditions (Vadivambal \& Jayas, 2011b). Also, thermal data registered in the thermal images may be used directly or indirectly in many diagnostic and quality control applications (Manickavasagan, Jayas \& White, 2008). With recent development in high-speed optical sensing tools and computer-integrated hardware and software, the thermal imaging methods have high potential in quality evaluation and inspection processes of various agricultural products with a high degree of accuracy and repeatability (Chitra, Suguna \& Sujatha, 2016). For instance, based on the temperature changes occurred during cooling and heating processes, thermal imaging method can be effectively 
used for remote detection of abnormality in agricultural products (Jamil \& Khairunniza-Bejo, 2014; Manickavasagan et al., 2008).

In agricultural applications, thermal imaging has been reported by many authors as a potential technique in many operations involved in agriculture such as detection of diseases and insect infestation in the whole plants, assessing seedling viability, estimating soil water status, evaluating crop water stress, identifying irrigation schedules, estimating crop yield and evaluating the maturity status of fruits and vegetables (Chelladurai, Jayas \& White, 2010; Manickavasagan, Jayas, White \& Paliwal, 2010; Manickavasagan, Jayas, White \& Paliwal, 2005; Vadivambal et al., 2011b). The apparent temperature provided by thermography is indirectly related to some functional or structural parameters like leaf orientation, heat capacity, surface properties, infrared absorption and transpiration rate (Fiorani, Rascher, Jahnke \& Schurr, 2012; Kaňa \& Vass, 2008). In seed quality evaluation, thermal imaging found its way in different sorts of applications including determination of overall seed quality, estimating the morphological features, detection of diseases and insect infestation, evaluation of germination performance and monitoring seed quality during storage. Compared to the conventional methods of seed quality evaluation, thermal imaging is more advantageous and expeditious over these techniques. For instance, the methods traditonally used for the assessment of fungal infection in seeds depend either on microbial culture techniques like plate agar methods or analyzing the volaltile compounds released from the seeds. Althoug these techniques give reliable results, they require a long observation and preparation period, specific laboratory arragement and skillful personnel to carry out the assessment. In this regard, infrared thermal imaging technique is a potential alternative for the remote, non-invasive detection of abnormalities in seeds depending on the temperature changes occurred during heating and cooling (Manickavasagan et al., 2008). Thence, installing a thermal imaging system in the storage facilities would be an appropriate tool to monitor stored seeds. Accordingly, this review is divided into two main sections. First, the theory and fundamentals of thermal imaging systems are explained in order to provide some useful information for professionals and seed analysts. Second, the potential applications of thermal imaging techniques to assess seed quality parameters are explored in more details.

\section{Principles of Thermal Imaging Technique}

As explained earlier, thermal infrared imaging is a technique to record the infrared radiation emitted from an object by an infrared detector and convert these records into two-dimensional temperature data called thermal image or thermogram that visualizes temperature distribution and gradients in all spots without a direct contact with the imaged object. Thermal imaging is a branch of remote sensing that deals with the acquisition, processing and interpretation of data acquired primarily in the thermal infrared portion of the electromagnetic spectrum (Al-doski, Mansor, Shafri \& Zulhaidi, 2016). In order to use thermal imaging techniques correctly, one should know the exact role of the thermal camera and 
the information it offers in the resulting thermal infrared images. Therefore, the theory and principles of the thermal imaging systems are explicitly explained in the following sections.

\subsection{Theory of Infrared Imaging}

As the thermal imaging technique utilizes the invisible infrared radiation emitted from an object to produce a pseudo image of the temperature gradients of the body's surface, the accuracy of the resulting thermograms or the thermal map depends basically on the capacity of the object for emitting infrared radiation. Most of the invisible infrared radiation characteristics are similar to those of visible light that can be focused, refracted, reflected, and transmitted. Thus, objects having a temperature above the absolute zero $\left(-273.15^{\circ} \mathrm{C}\right.$ or $\left.-459^{\circ} \mathrm{F}\right)$ emit such infrared radiation which is an invisible part of the electromagnetic spectrum in the wavelength region between $0.74 \mu \mathrm{m}$ to $1000 \mu \mathrm{m}$ (Ishimwe et al., 2014; Prakash, 2000). As shown in Figure 1, the electromagnetic spectrum consists of sub-regions including gamma rays, X-rays, ultraviolet radiation (UV), visible light (VIS), infrared radiation (IR), microwaves and radio waves (FM and AM). The infrared radiation $(0.74-1000 \mu \mathrm{m})$ is further divided into near

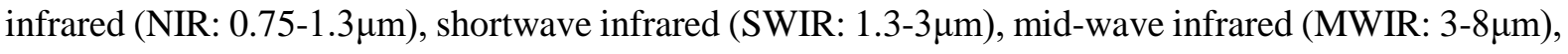
far-infrared or long-wave infrared (FIR or LWIR: 8-14 $\mu \mathrm{m}$ ) and extreme infrared (14-1000 $\mu \mathrm{m})$ regions. These divisions are based in the order of increasing wavelength and decreasing frequency by noting that the wavelength of the radiation increased to the right hand side and the frequency increases to the left hand side. It is noteworthy to indicate that the small window at wavelength range between 380 to $740 \mathrm{~nm}$ represents the visible spectrum of the radiation that can be sensed by human eyes and most of the living organisms.

Based on the characteristics of infrared radiation, the infrared region is preliminary classified into (i) reflected infrared that composed of near infrared and shortwave infrared and (ii) thermal infrared that composed of mid-wave infrared, long-wave infrared and extreme infrared regions. The near infrared (NIR) imaging systems available in the market usually measure the diffuse reflected radiation rather than emitted radiation. The mid- and long-wave regions are called the first and second thermal imaging bands, respectively (Holst, 2000). Typically, the long-wave infrared imaging systems are sensitive to low temperature such as room temperature, while the mid-wave infrared imaging systems have peak sensitivity at higher temperatures (e.g. $400{ }^{\circ} \mathrm{C}$ ) that may be suitable in detecting changes during food processing in various food industrial applications (Gowen, Tiwari, Cullen, McDonnell \& O'Donnell, 2010). Interpretation of data in short-wavelength range is rather complicated due to overlap with solar reflection in day imagery (Ishimwe et al., 2014). Therefore, the type of camera must be selected correctly based on application. Broadband cameras (sensitive to 3-12 $\mu \mathrm{m}$ ) and dual-wave band (long and short wave) cameras are available in the market (Manickavasagan et al., 2005). Although thermal imaging system can detect all infrared radiations in the electromagnetic spectrum at ambient temperature, only middle to far-infrared wavelength range $(3-15 \mu \mathrm{m})$ are commonly preferable in industrial food applications. 
In theory, the noninvasive thermal imaging method accesses the temperature records by using the blackbody law in which the amount of radiation emitted by an object depends on its temperature and emissivity $(\varepsilon)$ that links the energy emitted from the object to that of a blackbody at the same temperature and varies from 0 (a perfect white body) to 1 (a perfect blackbody). The blackbody itself is a theoretical object that absorbs and then emits all incident energy at all wavelengths. For a given wavelength $(\lambda)$ and temperature (T), the intensity of energy emitted by an object (I) is calculated from Planck's law as:

$$
I(\lambda, T)=\left(\frac{8 \pi h c}{\lambda^{5}}\right)\left(e^{h c / k \lambda T}-1\right)^{-1}
$$

where $h$ is Planck's constant $\left(6.626 \times 10^{-34} \mathrm{Js}\right)$; $\mathrm{c}$ is the speed of light $\left(3 \times 10^{8} \mathrm{~m} / \mathrm{s}\right), k$ is Boltzmann's constant $\left(1.38 \times 10^{-23} \mathrm{~J} / \mathrm{K}\right)$. Many devices used to measure spectra of radiation are measuring signals as a function of frequency $v=c / \lambda$ (in hertz) or wavenumber $\tilde{v}=1 / \lambda\left(\mathrm{in} \mathrm{cm}^{-1}\right.$ ) instead of wavelength $(\lambda)$ in the previous equation. By the way, the integration of the total energy intensity over all wavelengths in the range leads to Stefane-Boltzmann law as:

$$
\begin{aligned}
& E=\left[\frac{2 \pi^{5} k^{4}}{15 c^{2} h^{3}}\right] \times T^{4} \\
& E=\sigma T^{4}
\end{aligned}
$$

where $\mathrm{E}$ is the excitance or the total amount of radiation emitted per unit area of the object $\left(\mathrm{W} / \mathrm{m}^{2}\right) ; \sigma$ denotes the Stefane-Boltzmann constant $\left(5.67 \times 10^{-8} \mathrm{Wm}^{-2} \mathrm{~K}^{-4}\right)$ and $\mathrm{T}$ is the temperature $(\mathrm{K})$. As this law is used only for the standard blackbody; the term emissivity $(\varepsilon)$ is introduced in this equation to make it valid for real objects as:

$$
E=\varepsilon \sigma T^{4}
$$

Thence, estimating the surface temperature of an object in the scene requires the estimation of the total amount of radiation emitted per unit area of the object (E) and its emissivity (Hellebrand, Beuche \& Linke, 2002). As all materials vary in their emissivity, transmissivity, absorptivity, and reflectivity of infrared radiation, the sum of spectral absorption $(\alpha)$, reflection $(\rho)$ and transmission $(\tau)$ for any object is theoretically equal to $1(\alpha+\rho+\tau=1)$. In thermal imaging applications for opaque objects such as seeds and other food materials, there is no transmitted energy $(\tau=0)$ and the absorption is equal to emission $(\varepsilon=\alpha)$ according the Kirchhoff's law (Villaseñor-Mora, Martínez-Torres, Gonzalez-Vega, Borjas-García, Espinosa \& Hernandez, 2017) leading to $\varepsilon=1-\rho$ at a condition of thermal equilibrium of an object. The estimation of the emissivity of an examined object is experimentally determined by placing a thermometer on the targeted object or by placing an adhesive rubber of known emissivity on a part of the object (Belin et al., 2014). Moreover, the variation in emissivity value can be related with 
some other quality traits such as oil content, water content, and firmness of the object as well as geometric configuration of the object's surface.

However, the surrounding environmental conditions such as relative humidity (RH) and ambient temperature affect the received total radiation by the thermal camera. In practice, the total radiation $\left(\mathrm{E}_{\mathrm{Tot}}\right)$ received by a thermal camera is the sum of radiation emitted from the object itself $\left(\mathrm{E}_{\mathrm{Obj}}\right)$, radiation from ambient environment $\left(\mathrm{E}_{\mathrm{Amb}}\right)$ that has been reflected onto the object surface and the radiation from the surrounding atmosphere $\left(\mathrm{E}_{\mathrm{Atm}}\right)$ as expressed by (Bulanon, Burks \& Alchanatis, 2008):

$$
E_{T o t}=\varepsilon \tau E_{O b j}+(1-\varepsilon) \tau E_{A m b}+(1-\tau) E_{A t m}
$$

For calculating the total signal, this equation must be integrated over the wavelength to consider the spectral dependence of the detector responsivity and atmospheric transmission.

The values for object emissivity $(\varepsilon)$, the ambient and the atmospheric temperature can be entered directly into the camera software. Also, for blackbody radiation calculation, it is assumed that $(\varepsilon=1)$ and for short measurement distances it is assumed that $(\tau=1)$. Therefore, it is substantially important to correct the thermal data recorded by the thermal camera for the environmental changes. During real experiments on thermal imaging systems, care must be taken to maintain the system at thermal equilibrium in regard to the environment surrounding the target seeds and keeping the working distance between the seeds and the camera constant during the image acquisition to limit the absorption by the atmosphere and maximize the spatial resolution.

\subsection{Thermal Imaging System}

As shown in Figure 2, the typical system of infrared thermal imaging used for seed quality assessment mainly composed of two main components (1) a thermal camera along with optical units (focusing lens, collimating lens and filters) and thermal detector array such as microbolometers with the cooling or temperature stabilization unit and (2) a control and display unit equipped with a signal processing and image processing tool. To achieve a full functionality of the system with good accuracy and resolution to record the infrared radiation emitted from the target seeds, the characterizations of these components should be comprehensively elaborated (Gowen et al., 2010; Nanje Gowda \& Alagusundaram, 2013). It is also important to note that the thermal imaging system does not have an illumination unit like the other color or spectral imaging systems. The signal processing unit is responsible for translating and displaying the received electrical signals in a form of thermal records that show the temperature distribution over the target object surface in the scene. Thus, the thermal image obtained using this system is a matrix of many color levels each of which indicates a certain temperature. The scanning speed of thermal imaging devices in seed quality assessment is about 30 images per second with a sensitivity ranging from -20 to $1500^{\circ} \mathrm{C}$, which can be further increased by applying specific optical 
filters (Meola \& Carlomagno, 2004). In general, the thermal imaging system can be evaluated in terms different criteria such as scan speed, thermal sensitivity, image resolution and intensity resolution.

In essence, the core component of the thermal camera is the infrared detector that is responsible for absorbing the infrared radiation emitted by the object and converting this invisible radiation into electrical signals proportional to the amount of radiation falling on it (Vadivambal et al., 2011b). To a great extent, the quality of the transduction function of the detector determines the performance of the imaging system. By using the concepts of blackbody radiation, the sensitivity of thermal detectors can be estimated to identify the number of watts of input power onto a detector element, which is needed to detect a unit of temperature difference. Choosing the right types of detector in the thermal camera depends basically on the range of temperature to be sensed. In general, the detectors used in thermal cameras may be categorized into either thermal or photon detectors. In case of thermal detectors, the infrared radiation emitted from the target object falling on the detector surface heats up the detector element resulting in a temperature rise that can be subsequently measured by a temperature-dependent mechanism like thermoelectric voltage, resistance voltage or pyroelectric voltage (Rogalski, 2003; Vollmer \& Möllmann, 2017). On the other hand, in the case of photon or quantum detectors, the absorption of photons from infrared radiation by the detector results in a change of the electronic energy distribution in a semiconductor and leads to changes of concentration or mobility of the free charge carriers in the detector element via a process called photoelectric effect. The photon detectors could be categorized into classical semiconductor detectors including photonconductor and photondiodes and novel semiconductors detectors. Some examples of common photon-based detectors are the platinum silicide, cadmium mercury telluride (CMT) and the indium antimonide detectors. Generally, the photon detectors have greater sensitivity than the thermal detectors although the later ones are usually used in most of the food-sensing applications (Nanje Gowda et al., 2013). To add an advantage of thermal stability of the thermal imaging devices, the infrared detector may be enclosed in a cooling unit to maintain its working temperature around $0^{\circ} \mathrm{C}$ during the operation. Despite being rather expensive, these cooled detectors have a very high resolution and can detect temperature difference as low as $0.01^{\circ} \mathrm{C}$ that is why they are usually used in military and aerospace applications. For simple applications like food industrial applications, uncooled detectors can be safely used in which the infrared detector element is enclosed in a unit that operates under the ambient working temperatures (Vadivambal et al., 2011b).

As a complementary component of all cameras used in thermal imaging, lens is used to let light passes into the camera and to the detector. Although, all thermal cameras rely on infrared light to sense the thermal energy and do not employ visible lights to form the image, the lens is still an integral part of the camera. There are different designs of the lenses used with thermal cameras to either narrow or widen the field of view of the camera based on the applications and the size of the target objects. In general, such lenses used with thermal cameras are usually made of silicon ( $\mathrm{Si}$ ) or germanium $(\mathrm{Ge})$ 
materials. The silicon-based lenses are normally used for mid-wavelength cameras; meanwhile, the germanium-based lenses are utilized in long-wavelength cameras and both of them have good mechanical properties but quite expensive. For this reason, lenses used with the normal RGB camera cannot be used with imaging tasks with infrared cameras.

Despite the essential components of the thermal imaging system, there are two basic concepts for acquiring the image called the scanning and staring modes. In scanning mode, the image is build up sequentially line by line as a function of time similar to television screen. The detector in this case is a single element infrared detector that should be moved across the camera's field of view line by line. Unlike point scanning that measures a single point, the line-scanning mode senses multiple temperature points across a scan line. The camera is supported with a rotating mirror to measure the radiation along one horizontal line of the scene at a time and rotates vertically to scan a new horizontal line and so on. The motorized mirror scanning at high rate per second allows rapid detection of temperature gradient and any hot spots in the scene. At the end of the scanning process, a two-dimensional image (i.e. thermogram) is formed as the object moves across the field-of-view (Figure 3a). Thermal cameras equipped with line scan mode is more suitable for applications that involve moving objects like industrial and food processing engineering.

On the other hand, thermal image in the staring mode is projected simultaneously onto all pixels of the focal plan array (FPA) of the detector arranged in a matrix of rows and columns as shown in Figure $3 \mathrm{~b}$. Due to the absence of moving mechanical parts in the camera, the detector array of the staring imaging systems covers the whole field of view simultaneously for the entire frame time making such mode suitable for stable objects and for applications that do not include movement.

\subsection{Active and passive thermal imaging systems}

For practical applications of thermal imaging systems, the target object must possess a temperature different from its surroundings. This requires that the object should be either an energy source or an energy sink or to be heated or cooled before the imaging getting started. In addition, it is very important to consider that the temperature of the target objects may even change during observation. Principally, there are two different ways to distinguish objects by means of thermal imaging, i.e. either by differing emissivities or by using the different heat conductivities or capacities of the object materials. If two objects are different in their intrinsic emissivity coefficients, these two objects can be distinguished directly by infrared radiation released from them. Alternatively, applying a heat pulse over the objects and observing the radiation released from them could be used to discriminate among objects due to the difference in their heat conductivities (Ginesu, Giusto, Märgner \& Meinlschmidt, 2002). Thus, the two basic configurations used for building up an infrared thermographic imaging system in seed quality monitoring are the passive thermal imaging (that depends on emissivity principle) and the active thermal imaging approach (that depends on heat conductivity principle). In passive configuration, the thermal 
radiation emitted by the target body is monitored under natural conditions without employing an external energy to the system. The passive thermography is usually used when a heat is generated naturally by the tested objects. Therefore, the passive-based system is normally used to describe the surface thermal properties of the objects under investigation and for non-contact temperature measurement during processing. Also, it could be used to detect insect infestation in seeds because the respiration of insects within seed lots results in massive heat production higher than that of the sound seeds (Chelladurai, Kaliramesh \& Jayas, 2012; Damcevski, Annis \& Waterford, 1998; Emekci, Navarro, Donahaye, Rindner \& Azrieli, 2002; Emekci, Navarro, Donahaye, Rindner \& Azrieli, 2004; Manickavasagan et al., 2008). The passive configuration can be also used to predict the seed viability during imbibition due to some hyper and hypo thermal chemical reactions with definite thermal patterns that occur during this process that can be tracked by thermal imaging (Kranner, Kastberger, Hartbauer \& Pritchard, 2010).

In the second approach of thermal imaging, the emissivity is often not sufficient to offer well contrasted infrared images and it is advisable to heat or cool the samples before grabbing the thermal image frames. In the situations where it is not possible to obtain reasonable thermal signals it is advisable to apply an external energy source to create an adequate thermal contrast. The thermal imaging method used in these cases is called the active thermal imaging in which an external energy is deposited either by rapid cooling or heating the target objects prior to image acquisition (Gowen et al., 2010). In case of very small temperature difference, an excitation unit for increasing or decreasing the temperature of the object could be provided to increase temperature variations (Danno, Miyazato \& Ishiguro, 1980). The rate and distribution of temperature change throughout the object resulting after such exogenous heat treatment can be used to derive some relevant information about the thermal behavior of the object that in turn may be correlated to some other properties (Kuzy \& Li, 2015). In general, the temperature rise $(\Delta \mathrm{T})$ in biological objects like seeds after being heated depends principally on their specific heat $(\mathrm{Cp})$ as the heat gained $(\mathrm{Q})$ and the mass $(\mathrm{M})$ of the sample are constant (Manickavasagan et al., 2010):

$$
\Delta \mathrm{T}=\frac{\mathrm{Q}}{\mathrm{M}\left(\mathrm{C}_{\mathrm{p}}\right)}
$$

The thermographic investigation that involves heating or cooling process has been proven to present much more potentiality than the ordinary passive system (Theodorakeas, Cheilakou, Ftikou \& Koui, 2015). The active thermal imaging configuration achieved great results in food application such as detecting surface and sub-surface defects. In seed quality applications, the active system have been used successfully to detect fungal infection (Khairunniza-Bejo \& Jamil, 2013; Kheiralipour, Ahmadi, Rajabipour, Rafiee, Javan-Nikkhah \& Jayas, 2013), to detect seed impurities and distinguish damaged seeds (Jamil \& Khairunniza-Bejo, 2014; Vadivambal, Chelladurai, Jayas \& White, 2011a; Vadivambal, Chelladurai, Jayas \& White, 2010) and overall seed classification (Manickavasagan et al., 2010). The techniques used for generating thermal energy in active thermal imaging include (i) applying thermal 
excitation by a sinusoidal varying light source (such as halogen lamps or laser beam) to entice thermal energy to the target object in order to generate thermal waves that excite heat flow within the object tissues, (ii) applying ultrasonic waves for excitation the thermal energy in the target object, (iii) application of a short-term energy pulse of different durations for disturbing the thermal equilibrium within the object tissues and (iv) employing sonic waves to impart the surface of the target object without heating the object (Shepard, Ahmed \& Lhota, 2004).

\subsection{Processing of thermal images}

The real potential of any imaging system lies in its ability to provide quantitative information on spatial variation of the quantity being studied (Jones, 2004). The temperature distribution appeared in the thermograph could stand alone to characterize different features of the objects being imaged or to indirectly relate these thermal data with some hidden features. More importantly, for interpreting the data of surface temperature recorded in the thermal images, one must know all processes that might be involved in changing the object temperature. The thermograph obtained from a thermal camera can be analyzed using different sorts of image processing methods. Choosing one of these methods in analyzing data recorded in thermal images depends on the main goal of applications and the required speed of making a decision about the objects being imaged. For instance, in industrial settings, the processing method used in analyzing thermal images should be rapid and simple enough to fulfill realtime employment. These processing methods with pre-programmed algorithms are recently bundled in the thermal imaging cameras available in the market to estimate the temperature of target objects in the scene. For example, (Kim et al., 2013) used the software accompanied the FLIR thermal imaging system (FLIR systems, Burlington, Ontario, Canada) to process the thermal images of lettuce seeds in order to estimate the seed viability. Also, Smartview software coming with Fluke thermal imaging system (Fluke Thermography, Everett, WA, USA) was used by (Men, Yan, Liu, Qian \& Luo, 2017) to evaluate the viability of pea seeds and by (ElGamal, Kishk \& ElMasry, 2017) to analyze thermal images of paddy rice during drying process. Such ready-to-use software with pre-programmed image processing options can be used for preliminarily processing of thermal images and to obtain useful thermal information such as the averages, maximum and minimum values of seed temperatures. The built-in software could be used also for pre-processing of the thermal images for the purpose of removing dead pixels, reducing noise, filtering, deblurring, cropping, thresholding and masking.

For further processing of the acquired thermal images to obtain more thermal details from the acquired thermal images, many researches (Belin, Rousseau, Boureau \& Caffier, 2013; Belin et al., 2011; Chelladurai et al., 2012; Khairunniza-Bejo et al., 2013; Kim, Kim, Lohumi, Kang \& Cho, 2014) have developed various algorithms for post-processing operations of thermal images. If the temperature gradient distribution provided by thermal images was not enough to demonstrate the main purpose of the imaging process, complementary data mining or deep learning models could be developed to 
visualize hidden quality features of the target objects. This situation is also suitable when thermal images were acquired in time series to track possible changes occurred in the objects through the temporal domain. In general, to evaluate the relative advantages of any image processing methods of a thermal image over the others, some common performance indices such as processing time, model complexity, clarity of the results, classification accuracy, precision and ease of transfer to new thermal imaging systems should be considered.

\subsection{Factors affecting the quality of thermal images}

In real-time contactless temperature measurement with thermal imaging techniques, the radiation emitted from the objects in the camera's field of view must reach the detector with a certain intensity to be detected. The infrared radiation is required to travel the space between object surface and detector inside the camera housing. However, the emitted radiation from the objects is usually attenuated on this path due to the effect of the surrounding atmosphere and the solid focusing optics materials and filters it passes through. Therefore, it is quite important to know the scattering and absorption processes within the atmosphere in order to calculate the attenuation of the infrared radiation, which depends on the concentration of the absorbing gas species and relative humidity in the atmosphere.

In general, there are a number of factors that have a significant effect on the infrared thermal images during acquisition and on the interpretation of such images as well. In practice, it is rather difficult to control all of these factors, but being aware of those factors is essential in many application schemes (Roy, Das, Bhowmik \& Ghosh, 2016). As the main task of thermal imaging is to record the surface temperature of all objects in the field of view of the camera based on the thermal radiation emitted from these objects, factors that attenuate or augment this radiation before reaching the camera's detector should be thoroughly considered. For instance, some atmospheric conditions like temperature, relative humidity and wind velocity affect the transmission of infrared radiation from the target object to the thermal imaging system through attenuation via absorption or scattering. The atmosphere itself can emit radiation due to its high temperature which positively surge the radiation emitted from the objects. Thus, calibration of imaging system under working conditions is an essential step to make the system valid for comparing thermal data acquired at different periods (Ishimwe et al., 2014). The calibration step is essentially required to determine the accurate quantitative relationship between camera output $S_{o u t}\left(T_{b b}\right)$ and the incident radiation $L$. As a kind of simplicity, blackbodies $(\varepsilon=1)$ at different temperatures $\left(T_{b b}\right)$ are used for the calibration procedure because their radiometric properties and spectral quantities are well defined. During calibration, the camera aperture must be totally covered by an opaque cap with controlling all atmospheric emittance $\left(E_{A t m}=0\right)$. Hence, if there is an incident radiance with a magnitude of $L$ (in case of using active thermal imaging), the camera output signal 
$S_{\text {out }}\left(T_{b b}\right)$ for a given wavelength range extended from $\lambda_{1}$ to $\lambda_{2}$ depends only on the temperature of the blackbody $\left(T_{b b}\right)$ as explained in the following equation:

$$
S_{\text {out }}\left(T_{b b}\right)=\int_{\lambda_{1}}^{\lambda_{2}} \operatorname{Res}_{\lambda} L_{\lambda}\left(T_{b b}\right) d \lambda
$$

Besides, it is important to emphasize that the output signal of the camera depends also on the spectral response $\left(\operatorname{Res}_{\lambda}\right)$ of the camera, which is affected by the spectral responsivity of the detector, the optics transmittance and the characteristics of the camera optics such as the F-number of the lens. Moreover, installing filters with the imaging system affects the spectral response of the camera, and a recalibration procedure with the filter must be performed and saved in the camera's software. Once the relationship between the camera signal and blackbody temperature is defined, the camera can be used for the subsequent acquisitions of the target objects. It is also important to keep the distance between the camera and the blackbody as small as possible during the calibration process, so that the atmospheric transmittance is assumed to equal one.

Also, it is necessary when working at a specific condition to investigate the possible impact of the measuring environment on the information extracted from the scene (Belin et al., 2014). If the thermal camera was not kept in a status of thermal equilibrium, its performance would be rather poor in field experiments although it would have passed all required specifications during tests in the laboratory. Thus, it is better to operate the imaging system for couple of hours before being used to ensure the camera reached the thermal equilibrium condition.

The parameters that affect the performance of the imaging system can be divided into three basic groups based on their influence on the thermal images: (1) atmospheric parameters, (2) software parameters and (3) object and acquisition parameters. The atmospheric parameters affecting the generation of accurate thermal images include ambient temperature, atmospheric temperature, relative humidity, wind speed, solar load and shadow effects of nearby objects. The software factors that affect the accuracy of thermal images include the temperature range and color pallet used for image visualization. The third group of the factors affecting the resulting thermal images and their interpretation encompasses parameters related to object and hardware arrangement. These include wavelength range of the camera, angle of observation, distance between the object and the camera, object emissivity, optical properties of materials between camera and objects, moisture and thermal properties of objects, external optics temperature and transmission, object emissivity and the types of filters. Technically speaking, the performance of a fully calibrated thermal imaging system can be described by a number of features such as image quality, detector sensitivity, electronic noise, thermal response, geometric resolution, accuracy, spectral range, frame rate and integration time (Vollmer et al., 2017).

\section{Applications of Thermal Imaging in Seed Quality Assessment}


As the infrared thermal imaging technique is able to provide surface temperatures of the objects under investigation, the resulting thermal data can be used directly or indirectly for many applications. Thermal imaging technique has been proved as an innovative method in many fields especially in medical and engineering disciplines. After the noticeable reductions in the cost of the thermal imaging hardware and the advanced development occurred in the electronics and software designs, some new application opportunities were extended to other fields such as engineering, food and agriculture. Generally, when heat is generated or lost from the target object during observation and when the surface temperature of the object is important in quality determination and in sensing different quality attributes, the applicability of using thermal imaging scenarios is justified (Hellebrand et al., 2002).

In recent years, thermal imaging applications are multiple in research and development and gained great interests in agriculture and food industry. The potential uses of thermal imaging in agriculture and food industry have been reviewed by many authors (Al-doski et al., 2016; Gowen et al., 2010; Ishimwe et al., 2014; Manickavasagan, 2007; Manickavasagan et al., 2005; Nanje Gowda et al., 2013; Vadivambal et al., 2011b) indicating the importance of this emerged technology in different agro-food applications. As illustrated in Figure 4, thermal imaging systems of different designs have been successfully employed in different agricultural applications such as distinguishing soil surface crust, field nursery, detection of water stress in crops, yield forecasting, irrigation scheduling, identifying the ideal harvesting date, plant disease detection, fruit maturity evaluation, bruise detection, and monitoring of agricultural equipment (Danno et al., 1980; Fernandez-Gallego, Buchaillot, Aparicio Gutiérrez, NietoTaladriz, Araus \& Kefauver, 2019; Kuzy et al., 2015; Li, Zhang \& Huang, 2014; Manickavasagan, 2007; Meinlschmidt \& Maergner, 2003; Roy et al., 2016; Varith, Hyde, Baritelle, Fellman \& Sattabongkot, 2003; Villaseñor-Mora et al., 2017).

In food application practices, thermal imaging has demonstrated its ability in food engineering processes such as inspection and monitoring during processing operations, quality control and safety, detection of foreign materials, postharvest evaluation and packaging inspection. Recently, thermal imaging has found its way for various applications in various seed quality determination practices including viability estimation, detection of imbibition and germination, diseases detection, damage and impurities detection, variety identification and seed classification (Al-doski et al., 2016; Baranowski, Mazurek \& Walczak, 2003; Belin et al., 2011; Kranner et al., 2010; Manickavasagan, 2007). Therefore, this comprehensive review is provided to highlight various applications of this technique in the past few years and report all recent research efforts in using thermal imaging systems in seed quality monitoring. Figure 4 schematically illustrates the list of all reported applications of thermal imaging in agriculture, food and seed sectors.

\subsection{Seed viability estimation}


Viability assessment is an important topic for seed production and commercialization. Great interest has been directed on the definition and standardization of methods to test seed viability, germination and vigor, mostly depending on the expertise and the subjective evaluation by a seed analyst. The basic prerequisites for viability tests are the expeditiousness and inexpensiveness. Tests also need to be reproducible and uniformly interpretable (Dell'Aquila, 2007). Early detection of viable and nonviable seeds before planting will facilitate changing cultural practices before the situation getting worse and losing the investment (Belin et al., 2014; Belin et al., 2013; Eitel, Keefe, Long, Davis \& Vierling, 2010; Kranner et al., 2010). Therefore, thermal imaging technique has been proposed as a good alternative instead of the conventional methods of seed viability evaluation. The resulting thermal images provide thermal profiles of the seeds with demonstrated changes in temperature distribution that are strongly correlated with seed viability (Belin et al., 2018; Kranner et al., 2010), and this enables the distinguish of viable seeds from the nonviable ones (Zhang et al., 2018).

For testing seed viability and detecting abnormal and deed seeds, the imbibition rate during germination could be used as an indication of seed viability because seed germination rate depends with a great extent on the imbibition rate in most of seed species. In this regard, thermal imaging was used to examine seed imbibition and germination for different seed species such as pea, oilseed rape and wheat (Kranner et al., 2010). The results revealed that seed imbibition was associated with the changes occur in seed temperature during this process, which allows evaluating seed imbibition noninvasively. These changes in temperature can be used to detect nonviable seeds during the first $3 \mathrm{~h}$ of water uptake of imbibition and store the seeds again after the analysis without being killed (Belin et al., 2014). The thermal infrared data extracted from thermal images of the seeds could be used as a criterion for germination and this indicated that the biophysical and biochemical changes during imbibition and germination could be detected with thermal imaging and to predict whether a quiescent seed will germinate or die upon water uptake (Kranner et al., 2010). It is concluded that the thermal profiles during imbibition and germinating for viable, aged and deed seeds are significantly different due to varying thermogenic activities in seeds of different viability.

Infrared thermal imaging can be applied to detect the viability of seeds and seedlings, sense all possible physical damage and physiological disorders and monitor the growth process of seeds, seedlings and plants inside the nurseries and greenhouses. These capabilities came from the fact that there is a significant relationship between seedling temperature and the degree of damage (Hellebrand et al., 2002; Ljungberg \& Joensson, 2002) where the warmest seedlings had a lower survival rate than the cooler seedlings (Egnell \& Örlander, 1993). Therefore, thermal imaging was used to detect thermal signal decay characteristics that depend on seed aging conditions and seed viability (Kim et al., 2014). To evaluate the germination capacity of legume seeds, visible and thermal imaging systems were used by Baranowski et al. (2003) to record seed status during imbibition and germination processes. Thermal data and some other temperature-related parameters (minimum, maximum, average and standard 
deviation) were collected from every seed in the image and then statistically analyzed. The duration of seed storage and the variations in germination speed were shown to induce significant thermal differences during the initial stage of the imbibition and swelling process. The pattern of temperature changes of viable pea seeds showed a considerable decrease in the radiation temperature (more than $1{ }^{\circ} \mathrm{C}$ ) during the first 12 hours.

By using a passive thermal imaging system, the thermal profiles of garden pea seeds were acquired. A library of thermal fingerprints was constructed and used to discriminate between viable and dead seeds in less than two hours. The experimental works indicated that during imbibition the sugar within the seed dissolves leading to a rapid reduction in seed temperature by $2-3^{\circ} \mathrm{C}$. The viable seeds stay at this cool temperature because the storage reserves continuously break down into sugar, whereas certain biophysical properties of the aged seeds affect the speed of water uptake and fail to break down the food reserves and delay the thermal profile. This process is normally investigated with destructive methods by grinding up the seeds followed by biochemical assays; whereas the proposed infrared imaging method could be easily implemented for diagnosing this process noninvasively without affecting the properties of the viable seeds after testing.

For measuring the viability of lettuce seed, Kim et al. (2013) used an infrared lifetime thermal imaging system in the mid-infrared range $(1.5-5.0 \mu \mathrm{m})$ to record thermal emission signals of healthy and aged seeds. The obtained results indicated that the healthy and aged seeds are significantly different in terms of their lifetime thermal decay parameters and provided different visualized thermal maps as shown in Figure 5. In viable seed sample (control healthy seed), the decay amplitude of thermal radiation was greater than that of the artificially aged seed sample, and it decreased with increasing aging time (Figure 5a). On the contrary, the artificially aged seeds showed more delayed thermal radiation significantly higher than that of the healthy seeds (Figure 5b). This finding indicates the possibilities of using parameters extracted from thermal images for the non-destructive prediction of the viability status of the examined seeds.

The same technique was also used by Kim et al. (2014) for estimating the viability of pepper seeds where healthy and aged seeds were imaged at different periods $(24,48,72,96,120,144$, and 168h) and the extracted thermal data were analyzed by two-term exponential decay regression modeling. The results revealed that there is a significant difference between seed groups depending on the aging times. Moreover, the regression coefficient can be used to estimate the viability of each single seed based on the measured photo-thermal signals. In brief, the time-resolved photo-thermal parameters along with the regression coefficient images can be used to discriminate healthy seeds from the aged or dead ones. In another study carried out by Dumont et al. (2015), an active thermal infrared lifetime imaging technique was compared with SWIR hyperspectral imaging technique in evaluating the quality of Norway spruce (Picea abies (L.) Karst.) seeds. Both imaging techniques were used to identify viable, empty and infested seeds by the larvae of Megastigmus sp. The data of thermal signal decay of seeds 
after being exposed to a short light pulse were compared with the spectral data obtained from hyperspectral images in characterizing seed viability status using Support Vector Machine (SVM) and sparse logistic regression under leave-one-out cross validation (LOOCV). The results indicated that both imaging systems have great capabilities in seed classification compared to radiography classification. This finding nominates the combined utilization of hyperspectral and infrared lifetime imaging as a practical tool for non-destructive high-throughput seed screening. One of the big constrains in applying thermal imaging in real-time applications is that it requires scanning in temporal domain after applying a heat or light pulse. However, this problem could be alleviated by fixing the heating unit in one point in the conveyer belt and then installing the thermal camera in another point calculated precisely corresponding to the time required for receiving the radiation.

For the assessment of the viability of pea (Pisum sativum L.) seeds estimated by the root length after germination, infrared thermography technique was utilized by Men et al. (2017) for recording thermal and visible images every five minutes during a standard five day germination test. The visible images were segmented to identify the main region of interest and the location of each individual seed in the image from which the average temperature in the infrared images was extracted as the representative temperature for every seed and then plotted against time intervals. The parameters extracted from the temperature-time curve were analyzed via support vector machine (SVM) to classify seeds into three different levels of viability: viable, aged and dead. The results of analysis revealed that the classification accuracy rate was $91.67 \%$ using the temperature data within only the first three hours during the germination indicating the high potential of the infrared thermography classifying seeds to different viability classes.

After seed germination and development to a plant seedling, thermal imaging system still has a role in tracking the conditions of the growing plants because healthy transplants with good physiological properties are required for easy transplantation to field and higher yield of crops. In this sense, thermal imaging could be used for measuring some important invisible quality parameters like photosynthetic rate, chlorophyll content, and root activity (Kim et al., 2004). For instance, the viability of the one-year old 'Scots pine' (Pinus sylvestrur L.) and two-year old 'Norway spruce' (Picea abies (L.) Karst.) seedlings were determined by using infrared thermal imaging method (Egnell et al., 1993). The results of this study revealed that the warmer seedlings had a lower survival rate than the cooler seedlings and the relationship between seedling temperature difference and annual height increment was significantly correlated in a negative manner.

\subsection{Detection of diseases and infections}

Infections resulting from microbial spoilage and pest invasion represent severe problems in food industry and should be accurately detected and obviated. During storage, seeds undergo various biological and physicochemical changes besides being invaded by insect and pest infestation leading to 
huge quantitative and qualitative losses. Conditions such as high moisture content, excessive broken seeds and dockage provide favorable conditions for the infestation. These losses could be alleviated or even prevented by following proper storage conditions and monitoring the seeds for the presence of infection before getting developed further. The routinely used method for detection is usually conducted by sieving and manual inspection through different stages in seed and grain handling chain. However, these methods are not efficient with poor accuracy especially for massive seed production (Neethirajan, Jayas \& White, 2007). Recently, the detection procedure could be performed by using appropriate detection and control techniques such as thermal imaging followed by corrective measures (Veena, Arlene Christina \& Bided, 2015). Thermal imaging could play a strategic role in this trend and may act as an alternative method to detect insect infestation because the respiration of pests results in heat production higher than that of the seeds (Damcevski et al., 1998). In recent years, thermal imaging technique has become an important tool in diagnosis of disease and detection of insect infestation on seeds because failure of seed tissues due to disease progress are usually associated with difference on surface temperatures of the affected parts of the seeds.

\subsubsection{Detection of fungal infections}

The spoilage of seeds occurs due to unfavorable storage conditions resulting in inappropriate interactions between abiotic (temperature, moisture content and gases composition) and biotic (seed itself, insects, fungi, moulds and mites) factors. Heat and moisture are produced when seeds are attacked by mould or insects initiating a temperature rise in seeds and stimulating deteriorative effects. The major negative effects caused by fungal infection in seeds are reduction in germinability, discoloration of the seeds, heating and mustiness, radical changes in seed chemical composition, loss in dry matter leading to quantitative losses, and production of mycotoxins (Chelladurai, 2008). Therefore, early detection of infection occurred in seeds is very important to take early control actions. Besides being an easy-tohandle tool in diagnostics and monitoring of fungal and disease infections, thermal imaging technique provides useful information for detecting the progress of the diseases in a visualized form with extraordinary sensitivity and repeatability especially at the beginning of infection. Detection of temperature variations are commonly considered as a major diagnostic criterion in the diagnosis of such infection and infrared thermal imaging system is the right choice in this application.

In addition to its negative effects on the quality of the seeds in terms of appearance, germination and free fatty acid value in the infected seeds, fungal and mold infection affects the overall quantity by reduction of dry matter content and some other physicochemical treats. For instance, fungal infection increased the lipid content in wheat kernels by $0.5 \%$, the reducing sugar content up to 3 to 6 times and protein content up to $4-10 \%$ due to respiratory loss of carbohydrates. Such physicochemical changes induced by fungal growth may affect the temperature profiles of the seeds during heating and/or cooling. Accordingly, an active thermal imaging system was developed by Chelladurai et al. (2010) by heating 
the seeds for 180s and keeping them to cool for 30s to identify and classify the fungal infection in wheat seeds Three thermal images of wheat grains infected by Aspergillus glaucus, Aspergillus niger var Tieghem and Penicillium spp. were acquired: before heating, after heating and after cooling. The data of mean, minimum, maximum, median, mode and standard deviation of the surface temperatures were extracted from each image and analyzed using discriminant analysis modeling. The obtained results revealed that the temperature patterns of the infected seeds were significantly different from that of the healthy seeds. During heating phase, the surface temperature of the fungus-infected seeds rose to a degree higher than that of the healthy seeds. The rate of heating and cooling of the fungal-infected seeds was slightly higher than that of healthy kernels. These results emphasized the potential of the infrared thermal imaging system to detect fungal infection based on the change in temperature profiles it causes. By using the same protocol of active thermal imaging scheme, Khairunniza-Bejo et al. (2013) attempted to detect fungal infection in stored paddy. The characteristic of fungal infection in paddy was determined based on the average pixel of thermal graph against the time where the high temperature in the image results in higher pixel values. The results indicated that the average pixel of fungal-infected paddy has higher value (higher temperature) than that of the healthy paddy due to difference in the respiration rate and heat generation caused by fungi.

Similarly, Kheiralipour et al. (2013) tried to detect fungal infection in pistachio kernels infected by an aflatoxin-producing A. flavus isolate R5 and non-aflatoxin-producing isolate KK11 using an active thermal imaging system. Thermal images were acquired for both healthy and infected seeds before heating, directly after heating at $90^{\circ} \mathrm{C}$ for $90 \mathrm{~s}$ and after being cooled at room temperature for $10 \mathrm{~s}$. A threshold classification algorithm was developed and evaluated for classification of thermal imaging data of healthy and fungal-infected pistachio kernels. Results showed that the developed method can be used to accurately classify the healthy and fungal-infected pistachio kernels based on their thermal profiles.

\subsubsection{Detection of insect infestation}

The detection process of insect infestation in seeds is not an easy task because insects are living organisms and concealed inside seeds with no external symptoms or signs of infestations in many circumstances. The standard methods suggested by the International Standard Organization (ISO, 1987) used for the traditional determination of the degree of insect infestations in seeds are: estimation of carbon dioxide production, ninhydrin reaction with amino acids, grain flotation method, acoustic method, and X-ray method. As a non- destructive and rapid technique, infrared thermal imaging technique offers another approach for detecting insect infestation in seeds and grains. Based on the temperature difference and heat production due to insect respiration, thermal imaging technique has a great potential in detecting all insect post-embryonic stages (Emekci et al., 2002; Emekci et al., 2004). The technique offers a reliable option to detect hidden infestation of all life stages of insects (egg, pupae, 
larva and adult) inside seeds by recording the hot surface temperature and thermal profiles created by insects' respiration. The heat produced by insects is usually higher than that produced by the normal seeds that can be easily detected even by using passive thermal imaging systems without employing an external heating source.

Manickavasagan et al. (2008) investigated the feasibility of a passive thermal imaging system to detect the presence of insects inside wheat kernels at six development stages. Thermal images were acquired of wheat kernels artificially infested by eggs of rusty grain beetle (Cryptolestes ferrugineus) at 4, 8, 11, 15, 22, and 27 days after infestation corresponding to four larval stages, pupal, and adult stages, respectively. The temperature distribution on the surface of the infested kernels with different stages of C. ferrugineus was highly correlated with the respiration rate of each developmental stage. Based on surface temperature parameters extracted from thermal images, the results obtained from this study revealed that thermal imaging technique was effective in distinguishing infested and healthy grains using either linear or quadratic discriminant models, but is less effective in identifying the developmental stage of infection. In pairwise discrimination, the overall classification accuracy for infested and sound kernels was $83.5 \%$ and $77.7 \%$ using quadratic discrimination model and $77.6 \%$ and $83.0 \%$ for linear discrimination model, respectively.

The same research group (Chelladurai et al., 2012) utilized the same research protocols to detect infestation by cowpea seed beetle (Callosobruchus maculatus) in mung bean (Vigna radiata). Thermal images were acquired for healthy and beans infested by eggs, larvae and pupa of $C$. maculatus (F.). Thermal profiles and temperature parameters were extracted from thermal images and analyzed by linear and quadratic discriminant models. The results of this study has proven the capability of thermal imaging technique in detecting insect infestation and the quadratic discriminant model provided better classification accuracy compared to the linear models. Also, the quadratic model correctly identified more than $80 \%$ of mung beans infested with initial stages of C. maculatus infestation.

\subsection{Detection of impurities and seed damage}

After crop harvesting, seeds are normally contaminated with some impurities such as foreign substances, husks, plant debris, weed seeds and damaged and dead seeds. Foreign substances themselves may be defined as any undesirable materials (dirt, chaff, stones, weed, straw, stalks, dead insects, rat excreta etc.) exist in the final seed lot. The high quality seed lot should be genetically pure, not mixed with seeds of other species, free from diseases and characterized by a high viability (Dumont et al., 2015). One of the big challenges facing seed industry is to check the impurities and eliminate damaged seeds and foreign materials from the seed lots. Distinguishing seed varieties and ensuring the seed purity has a great effect in seed production and plant breeding practices. The process is complemented by applying integrated operations for checking the presence of foreign materials, weed seeds, dead and damaged kernels and other impurities. A damaged seed is not necessarily to be broken, 
damaged seed could be that one that is unable to germinate or those seeds that germinated during storage in which the germ end is opened due to germination and exhibiting a sprout, or those in which the sprouts had been broken off leaving only the socket. Thus sprouting results in harvest losses, reduced grain weight, loss of seed viability, and increase in amylase enzyme activity (Vadivambal et al., 2010). The detection can be easily accomplished by simple measurements of the essential morphological features such color, shape and dimensions. In this sense, thermal imaging technique has proved potential applications in detecting seed damage and impurities.

An active thermal imaging system was employed by Vadivambal et al. (2010) and Vadivambal et al. (2011a) instead of the ordinary methods such as falling number, stirring number and rapid visco analyzer for the detection of sprout-damaged kernels in barley and wheat. The detection protocol involved heating the kernels by a hot plate at $30 \pm 1^{\circ} \mathrm{C}$ and thermal images were acquired in the spectral range of $7.5-13 \mu \mathrm{m}$. Temperature features were extracted from images and analyzed by for possible discrimination between healthy and sprouted kernels using linear and quadratic discriminant models and artificial neural network classifiers. Results revealed that significant difference is exist between the temperature data of healthy and sprout-damaged kernels because the respiration and heat energy released from damaged kernels are higher than that from healthy ones (Figure 6). This finding led to accurate classification models $(88.2-99.4 \%)$ between both classes confirming the capacity of the thermal imaging method in identifying sprout-damaged wheat and barley kernels from the healthy ones. Thermal imaging system with a thermal sensitivity of $0.05^{\circ} \mathrm{C}$ and operated in mid infrared region of wavelength was used to detect paddy husk by Jamil \& Khairunniza-Bejo (2014) by employing heating and cooling treatments for paddy samples having different husk contents (20, 40, 60 and 100\%) before being thermally imaged. Due to the difference in heat transfer capacity between paddy seeds and husks, the obtained results showed a difference in surface temperature between husk and paddy seeds as show in Figure 7. A cooling cycle of 25 s provided the highest discrimination between paddy seeds and husks with high classification accuracy of $98.07 \%$. As shown in Figure 7, the proposed technique was very effective in detecting husks in paddy seeds in all examined samples despite the amount of husks presented in the samples. Because husk has lower thermal conductivity and lower temperature, it always appears darker in the thermal images and can be easily detected by simple thresholding (Figure 7b). For clarity, the analysis of a thermal image containing $100 \%$ paddy seeds resulted in a black binary image (zero husk pixels detected) because it does contain any husks in the sample.

As the immature paddy normally causes low milling recovery, high percentage of broken rice, poor grain quality and more chances of disease attacks during storage, such seeds are considered as foreign materials and should be entirely eliminated from the lot. Therefore, Khairunniza-Bejo, Azman \& Jamil (2016) used the same procedure to detect paddy seeds having different levels of foreign substances, maturity condition and moisture content. Thermal videos were acquired for paddy samples after being heated and cooled, and some frame images were extracted and analyzed. After segmenting seed samples 
from the thermal image frames, the average value of all pixels belonging to the sample were calculated to express the average surface temperature of the sample. The calculated average surface temperature of a sample was expressed as the sample's thermal index. Results of maturity stage determination had shown that there was a significant linear relationship between thermal index values extracted from thermal images and the paddy maturity stage with $\mathrm{r}$ of 0.896 . The more matured the paddy was, the higher the mean pixel value (thermal index) would be. This method also successfully predicted paddy seeds of different moisture contents with $\mathrm{r}$ of -0.948 . The results of the chaff detection in paddy had shown that the mean pixel value (the mean temperature or thermal index) of the seeds in the thermal image is higher compared to that of chaff pieces. Similar to the previous study, the mean pixel value after $25 \mathrm{~s}$ of cooling gave a good separation between paddy seeds and chaff.

Several conventional methods of separating impurities including visual inspection, physical separation and gravity separation methods (e.g. sieving, elutriation, sedimentation, screening and filtering) are recently employed. In spite of the accuracy of all of these methods, a considerable portion of the foreign materials remain undetected. Also, there is no single devices that can detect all types of contaminants regardless of size, shape and type (Vadivambal et al., 2011b). Therefore, Meinlschmidt et al. (2003) developed a thermal imaging setup to detect foreign substances like rotten nuts, hard shells, and stones in hazelnuts during their continuous movement over a conveyor belt. By using three different image processing routines, object-oriented algorithms for grains and online thermal imaging were developed. The physical behaviour of food and foreign materials, their shape and quality of the images were considered as detection parameters.

Moreover, Ginesu, Giusto, Märgner \& Meinlschmidt (2004) used adaptive banalization, statistical and morphological analysis to find the feasibility of thermal imaging to detect the stones in almond, cardboard pieces in almond, wooden sticks in raisins, metal chips in almond and cardboard pieces in nuts. In this study, mathematical morphology was specially designed to solve the problem of separating foreign materials. Before analysis and recognition of foreign substances is done, preprocessing was performed in order to enhance the image information content including dead pixel correction, filtering enhancement, shading correction, and histogram stretching.

\subsection{Seed classification and variety identification}

In addition to the essential physicochemical parameters, the standard seed testing approach should be conducted also to check varietal purity, soundness, germination ability, vigor and seed health and uniformity. These specific testing procedures are substantially important to improve the seed acceptability, storage life, market value, and export potential. Therefore, new inspection tools should be sought for the purpose of identification and classification of excellent seed varieties, which are visually alike and hard to differentiate by traditional methods. Hence, research efforts are still needed to develop advanced systems for the assessment of seed heterogeneity, variety grading and presence of 
foreign substances. Unfortunately, these research attempts in variety identification and seed classification using thermal imaging is very limited even though it has great potential to offer high classification accuracy compared with the other methods that are subjective, troublesome, and inconsistent in many circumstances (Majumdar \& Jayas, 2000).

Manickavasagan et al. (2010) explored the ability of thermal imaging technique to categorize different wheat varieties. An active thermal imaging system supported with a heating unit was used for the acquisition of thermal images of eight western Canadian wheat varieties after being heated for 180s and cooled for 30s. The analysis of the acquired thermal images revealed that the responses of the examined varieties for the heating and cooling cycles were significantly different. The temperature rise (after heating) ranged from 14.94 to $17.80^{\circ} \mathrm{C}$, and the temperature drop (after cooling) ranged from 3.67 to $4.42{ }^{\circ} \mathrm{C}$ for the Canada Western Red Spring and Canada Prairie Spring Red varieties, respectively. For the classification task using the quadratic discriminant analysis modeling, the results showed that the overall classification accuracy was in the range of $76-95 \%$ for eight-class classification, $64-87 \%$ for four-class classification and $91 \%$ for two-class classification models. In general, during the development of a thermal imaging technique for variety identification and classification, some other important factors such as growing season, defects, and kernel size should also be also considered. More interestingly, the rate of heating and cooling was found to be negatively correlated with protein content with correlation coefficient $r$ of -0.63 and -0.65 and true density with $r$ of -0.67 and -0.71 and positively correlated with grain hardness with $\mathrm{r}$ of 0.41 and 0.53 for heating and cooling cycles, respectively. This finding is in agreement with that reported by Zhang \& Brusewitz (1990) who indicated that the temperature rise of heated biological materials like grains is a function of their moisture content.

In another study, Manickavasagan (2007) used an active thermal imaging for the discriminating the seeds of wheat, barley and canola after being dried using a pilot scale microwave drier for 28 and $56 \mathrm{~s}$ at five different power levels to check the difference in the heating non-uniformity (difference between maximum and minimum temperatures) among these grain types. The results of this study indicated that the grain type had a significant effect on the surface temperatures after microwave treatment. Thus, the difference between the maximum and minimum surface temperatures $(\Delta T)$ of wheat, barley and canola were 62.9 to $69.5^{\circ} \mathrm{C}, 64.3$ to $75.6^{\circ} \mathrm{C}$ and 39.5 to $59.2^{\circ} \mathrm{C}$ respectively, when the grains were exposed to $500 \mathrm{~W}$ power level for $56 \mathrm{~s}$. Also, the non-uniform heating patterns were observed for all three grain types at all moisture contents, power levels, and exposure times. These results should be considered when developing microwave processing systems for grains. On the other hand, the germination percentage and the fat acidity value (FAV) were significantly different for samples collected from high temperature region than those from the normal temperature zones in the seed lot.

\section{Conclusion}


Thermal imaging is an emerging technology recently implemented in food science and technology for non-invasive and non-contact sensing of thermal properties of different food products and linking these measurements with intrinsic quality traits either during or after processing. The technique has been moved from just an exploration method in engineering and astronomy into an effective tool in food science and technology. Based on the thermal properties of the examined products, the transmitted radiation relies basically on the surface temperature of the products, meaning that the higher the temperature of the target products is, the more emitted radiation will be. Thus, thermal imaging techniques have been studied in details by many researchers and the outcomes of research yielded valuable applications in agricultural and food industry. Similar to these applications, thermal imaging methods have been also used for seed monitoring and quality evaluation assessment. This article has briefly explored the fundamentals and main configuration of this technique and its major applications in seed quality evaluation. The method has been successfully utilized in many critical assessment in seed quality evaluation such as determination of seed viability, detection of fungal growth, detection of insect infection, and estimation of seed damage and impurities. Thermal imaging is increasingly accepted by many researchers as a supplementary diagnostic and monitoring tool for various seed diseases based on the fact that diseases, defects, blemishes and injuries cause severe changes in surface temperature that can be easily captured by using sensitive thermal cameras. Despite its capability of numerous applications, thermal imaging has a few downsides compared with other imaging techniques in terms of cost margins and sensitivity to the surrounding environment. However, improvement in detector design, hardware adaptation and improved capabilities of the digitized image-processing algorithms will boost this technology forward towards more practical applications especially in highthroughput implementations in seed industry that would not be possible by the other conventional methods. The research conducted in this field shows that there is still endeavors and opportunities for further potential applications in seed science and technology. Hence, further research should be focused in developing low-cost infrared detectors with higher accuracy for facilitating this technique in largescale industrial applications adaptable under harsh working environments.

\section{Conflict of interest}

Authors declare that they have no conflict of interest.

\section{Acknowledgements}

Authors significantly acknowledge the financial support from STDF-IRD-AUF joint research project provided by Egyptian Science and Technology Development Fund (STDF), Marie Sklodowska-Curie COFUND P-SPHERE project under the European Union's Horizon 2020 research and innovation 
programme with grant agreement No665919 and the Distinguished Scientist Fellowship Program (DSFP) King Saud University.

\section{References}

Al-doski, J., Mansor, S. B., Shafri, H., \& Zulhaidi, H. (2016). Thermal imaging for pests detecting - a review. International Journal of Agriculture, Forestry and Plantation, 2, 10-30.

Baranowski, P., Mazurek, W., \& Walczak, R. (2003). The use of thermography for pre-sowing evaluation of seed germination capacity. In: International Conference on Quality in Chains. An Integrated View on Fruit and Vegetable Quality, vol. 604 (pp. 459-465).

Belin, E., Douarre, C., Gillard, N., Franconi, F., Rojas-Varela, J., Chapeau-Blondeau, F., Demilly, D., Adrien, J., Maire, E., \& Rousseau, D. (2018). Evaluation of 3D/2D Imaging and Image Processing Techniques for the Monitoring of Seed Imbibition. Journal of Imaging, 4(7), 83.

Belin, É., Rousseau, D., Benoit, L., Demilly, D., Ducournau, S., Chapeau-Blondeau, F. o., \& Dürr, C. (2014). Thermal imaging for evaluation of seedling growth. In: S. Dutta Gupta, \& Y. Ibaraki, Plant Image Analysis: Fundamentals and Applications (pp. 165-178). 6000 Broken Sound Parkway NW, USA: CRC Press, Taylor \& Francis Group.

Belin, É., Rousseau, D., Boureau, T., \& Caffier, V. (2013). Thermography versus chlorophyll fluorescence imaging for detection and quantification of apple scab. Computers and Electronics in Agriculture, 90, 159-163.

Belin, É., Rousseau, D., Rojas-Varela, J., Demilly, D., Wagner, M.-H., Cathala, M.-H., \& Dürr, C. (2011). Thermography as non invasive functional imaging for monitoring seedling growth. Computers and Electronics in Agriculture, 79(2), 236-240.

Boelt, B., Shrestha, S., Salimi, Z., Jørgensen, J. R., Nicolaisen, M., \& Carstensen, J. M. (2018). Multispectral imaging-a new tool in seed quality assessment? Seed Science Research, 28(3), 222-228.

Bulanon, D., Burks, T., \& Alchanatis, V. (2008). Study on temporal variation in citrus canopy using thermal imaging for citrus fruit detection. Biosystems Engineering, 101(2), 161-171.

Chaerle, L., De Boever, F., Montagu, M. V., \& Straeten, D. V. D. (2001). Thermographic visualization of cell death in tobacco and Arabidopsis. Plant, Cell \& Environment, 24(1), 15-25. 
Chaerle, L., Van Caeneghem, W., Messens, E., Lambers, H., Van Montagu, M., \& Van Der Straeten, D. (1999). Presymptomatic visualization of plant-virus interactions by thermography. Nature Biotechnology, 17(8), 813.

Chelladurai, V. (2008). Identification of fungal infection in wheat using thermal imaging technique. PhD Dissertation, Department of Biosytems Engineering. Manitoba, Canada: University of Manitoba.

Chelladurai, V., Jayas, D., \& White, N. (2010). Thermal imaging for detecting fungal infection in stored wheat. Journal of Stored Products Research, 46(3), 174-179.

Chelladurai, V., Kaliramesh, S., \& Jayas, D. (2012). Detection of Callosobruchus maculatus (F.) infestation in mung bean (Vigna radiata) using thermal imaging technique. NABECCSBE/SCGAB 2012 Joint Meeting and Technical Conference. Lakehead University, Orillia, Ontario, Canada.

Chitra, H. S. H., Suguna, S., \& Sujatha, S. N. (2016). A survey on image analysis techniques in agricultural product. Indian Journal of Science and Technology, 9(12), 1-13.

Damcevski, K., Annis, P., \& Waterford, C. (1998). Effect of grain on apparent respiration of adult stored-product Coleoptera in anair-tight system: implications for fumigant testing. Journal of Stored Products Research, 34(4), 331-339.

Danno, A., Miyazato, M., \& Ishiguro, E. (1980). Quality evaluation of agricultural products by infrared imaging method. III. Maturity evaluation of fruits and vegetables. Memoirs of the Faculty of Agriculture, Kagoshima University, 16, 157-164.

Dell'Aquila, A. (2004). Application of a computer-aided image analysis system to evaluate seed germination under different environmental conditions. Italian Journal of Agronomy, 8(1), 5162.

Dell'Aquila, A. (2007). Towards new computer imaging techniques applied to seed quality testing and sorting. Seed Science and Technology, 35(3), 519-538.

Dumont, J., Hirvonen, T., Heikkinen, V., Mistretta, M., Granlund, L., Himanen, K., Fauch, L., Porali, I., Hiltunen, J., \& Keski-Saari, S. (2015). Thermal and hyperspectral imaging for Norway spruce (Picea abies) seeds screening. Computers and Electronics in Agriculture, 116, 118-124.

Egnell, G., \& Örlander, G. (1993). Using infrared thermography to assess viability of Pinus sylvestris and Picea abies seedlings before planting. Canadian Journal of Forest Research, 23(9), 17371743.

Eitel, J., Keefe, R., Long, D., Davis, A., \& Vierling, L. (2010). Active ground optical remote sensing for improved monitoring of seedling stress in nurseries. Sensors, 10(4), 2843-2850. 
ElGamal, R. A., Kishk, S. S., \& ElMasry, G. M. (2017). Validation of CFD models for the deep-bed drying of rice using thermal imaging. Biosystems Engineering, 161(1), 135-144.

ElMasry, G., Kamruzzaman, M., Sun, D. W., \& Allen, P. (2012). Principles and applications of hyperspectral imaging in quality evaluation of agro-food products: a review. Critical Reviews in Food Science \& Nutrition, 52(11), 999-1023.

ElMasry, G., Mandour, N., Al-Rejaie, S., Belin, E., \& Rousseau, D. (2019a). Recent Applications of multispectral imaging in seed phenotyping and quality monitoring - An overview. Sensors, 19(5), 1090.

ElMasry, G., Mandour, N., Wagner, M.-H., Demilly, D., Verdier, J., Belin, E., \& Rousseau, D. (2019b). Utilization of computer vision and multispectral imaging techniques for classification of cowpea (Vigna unguiculata) seeds. Plant methods, 15(1), 24.

ElMasry, G., \& Nakauchi, S. (2016). Image analysis operations applied to hyperspectral images for non-invasive sensing of food quality-A comprehensive review. Biosystems Engineering, 142(1), 53-82.

Emekci, M., Navarro, S., Donahaye, E., Rindner, M., \& Azrieli, A. (2002). Respiration of Tribolium castaneum (Herbst) at reduced oxygen concentrations. Journal of Stored Products Research, 38(5), 413-425.

Emekci, M., Navarro, S., Donahaye, E., Rindner, M., \& Azrieli, A. (2004). Respiration of Rhyzopertha dominica (F.) at reduced oxygen concentrations. Journal of Stored Products Research, 40(1), 27-38.

Fernandez-Gallego, J. A., Buchaillot, M., Aparicio Gutiérrez, N., Nieto-Taladriz, M. T., Araus, J. L., \& Kefauver, S. C. (2019). Automatic wheat ear counting using thermal imagery. Remote Sensing, 11(7), 751.

Fiorani, F., Rascher, U., Jahnke, S., \& Schurr, U. (2012). Imaging plants dynamics in heterogenic environments. Current opinion in Biotechnology, 23(2), 227-235.

Ginesu, G., Giusto, D. D., Märgner, Volker, \& Meinlschmidt, P. (2002). Detection of foreign bodies in food by thermal imagery. In: JAPR Workshop on Machine Vision Application (pp. 128-131). Nara, Japan.

Ginesu, G., Giusto, D. D., Märgner, V., \& Meinlschmidt, P. (2004). Detection of foreign bodies in food by thermal image processing. IEEE Transactions on Industrial Electronics, 51(2), 480-490.

Gowen, A. A., Tiwari, B. K., Cullen, P. J., McDonnell, K., \& O'Donnell, C. P. (2010). Applications of thermal imaging in food quality and safety assessment. Trends in Food Science \& Technology, 21(4), 190-200. 
Guidetti, R., Beghi, R., \& Giovenzana, V. (2012). Chemometrics in Food Technology. In: K. Varmuza, Chemometrics in Practical Applications: InTech, Slavka Krautzeka 83/A 51000 Rijeka, Croatia.

Hellebrand, H. J., Beuche, H., \& Linke, M. (2002). Thermal Imaging. In: J. Blahovec, \& M. Kutílek, Physical Methods in Agriculture- Approach to Precision and Quality (pp. 411-427): Springer.

Holst, G. C. (2000). Common sense approach to thermal imaging. SPIE Optical Engineering Press Washington, USA.

Huang, M., Wang, Q., Zhu, Q., Qin, J., \& Huang, G. (2015). Review of seed quality and safety tests using optical sensing technologies. Seed Science and Technology, 43(3), 337-366.

Ishimwe, R., Abutaleb, K., \& Ahmed, F. (2014). Applications of thermal imaging in agriculture - a review. Advances in Remote Sensing, 3(3), 128-135.

ISO (1987). Cereals and pulses — Determination of hidden insect infestation — Part 4: Rapid methods. vol. ISO 6639-4:1987: International Standard Organization (ISO), https://www.iso.org/standard/13066.html.

Jamil, N., \& Khairunniza-Bejo, S. (2014). Husk detection using thermal imaging technology. The $2^{\text {nd }}$ International Conference on Agricultural and Food Engineering, CAFEi2014", Agriculture and Agricultural Science Procedia, 2, 128-135.

Jones, H. G. (2004). Application of thermal imaging and infrared sensing in plant physiology and ecophysiology. Advances in Botanical Research, vol. 41 (pp. 107-163): Elsevier, The Nethrlands.

Kaňa, R., \& Vass, I. (2008). Thermoimaging as a tool for studying light-induced heating of leaves: Correlation of heat dissipation with the efficiency of photosystem II photochemistry and nonphotochemical quenching. Environmental and Experimental Botany, 64(1), 90-96.

Khairunniza-Bejo, S., Azman, N., \& Jamil, N. (2016). Paddy grading using thermal imaging technology. International Food Research Journal, 23, S245.

Khairunniza-Bejo, S., \& Jamil, N. (2013). Preliminary study on detection of fungal infection in stored paddy using thermal image. International Proceedings of Chemical, Biological and Environmental Engineering, 60, 19-23.

Kheiralipour, K., Ahmadi, H., Rajabipour, A., Rafiee, S., Javan-Nikkhah, M., \& Jayas, D. (2013). Development of a new threshold based classification model for analyzing thermal imaging data to detect fungal infection of pistachio kernel. Agricultural Research, 2(2), 127-131. 
Kim, G., Kim, G.-H., Lohumi, S., Kang, J.-S., \& Cho, B.-K. (2014). Viability estimation of pepper seeds using time-resolved photothermal signal characterization. Infrared Physics \& Technology, 67, 214-221.

Kim, G., Kim, G., Ahn, C.-K., Yoo, Y., \& Cho, B.-K. (2013). Mid-infrared lifetime imaging for viability evaluation of lettuce seeds based on time-dependent thermal decay characterization. Sensors, 13(3), 2986-2996.

Kim, Y. H., \& Lee, S. H. (2004). Thermal and visual image characteristics of potato transplants as affected by photosynthetic photon flux and Electric conductivity. In: 2004 ASABE Annual Meeting (p. ASABE Paper No. 044101). Ottawa, Canada: American Society of Agricultural and Biological Engineers.

Kranner, I., Kastberger, G., Hartbauer, M., \& Pritchard, H. W. (2010). Noninvasive diagnosis of seed viability using infrared thermography. Proceedings of the National Academy of Sciences, 107(8), 3912-3917.

Kuzy, J. D., \& Li, C. (2015). Blueberry Bruise Detection by Pulse-Phase Thermography and Neural Network. In: 2015 ASABE Annual International Meeting. New Orleans, Louisiana, USA: American Society of Agricultural and Biological Engineers.

Li, L., Zhang, Q., \& Huang, D. (2014). A review of imaging techniques for plant phenotyping. Sensors, 14(11), 20078-20111.

Ljungberg, S.-A., \& Joensson, O. (2002). Infrared thermography: a tool to map temperature anomalies of plants in a greenhouse heated by gas fired infrared heaters. In: Thermosense XXIV, vol. 4710 (pp. 399-406): International Society for Optics and Photonics.

Majumdar, S., \& Jayas, D. (2000). Classification of cereal grains using machine vision: I. Morphology models. Transactions of the ASAE, 43(6), 1669.

Manickavasagan, A. (2007). Thermal imaging for potential use in cereals and oilseeds handling. Department of Biosystems Engineering, vol. PhD. Winnipeg, Manitoba, Canada: University of Manitoba.

Manickavasagan, A., Jayas, D., \& White, N. (2008). Thermal imaging to detect infestation by Cryptolestes ferrugineus inside wheat kernels. Journal of Stored Products Research, 44(2), 186-192.

Manickavasagan, A., Jayas, D., White, N., \& Paliwal, J. (2010). Wheat class identification using thermal imaging. Food and Bioprocess Technology, 3(3), 450-460.

Manickavasagan, A., Jayas, D. S., White, N. D., \& Paliwal, J. (2005). Applications of thermal imaging in agriculture - a review. In: The CSAE/SCGR 2005 Meeting, . Winnipeg, Manitoba, Canada. 
Meinlschmidt, P., \& Maergner, V. (2003). Thermographic techniques and adapted algorithms for automatic detection of foreign bodies in food. In: Thermosense XXV, vol. 5073 (pp. 168-177): International Society for Optics and Photonics.

Men, S., Yan, L., Liu, J., Qian, H., \& Luo, Q. (2017). A classification method for seed viability assessment with infrared thermography. Sensors, 17(4), 845.

Meola, C., \& Carlomagno, G. M. (2004). Recent advances in the use of infrared thermography. Measurement Science and Technology, 15(9), R27.

Milošević, M., Vujaković, M., \& Karagić, Ä. u. (2010). Vigour tests as indicators of seed viability. Genetika, 42(1), 103-118.

Nanje Gowda, N., \& Alagusundaram, K. (2013). Use of thermal imaging to improve the food grains quality during storage. International Journal of Current Agricultural Research, 1(7), 34-41.

Neethirajan, S., Jayas, D., \& White, N. (2007). Detection of sprouted wheat kernels using soft X-ray image analysis. Journal of Food Engineering, 81(3), 509-513.

Panagou, E. Z., Papadopoulou, O., Carstensen, J. M., \& Nychas, G.-J. E. (2014). Potential of multispectral imaging technology for rapid and non-destructive determination of the microbiological quality of beef filets during aerobic storage. International Journal of Food Microbiology, 174, 1-11.

Prakash, A. (2000). Thermal remote sensing: concepts, issues and applications. International Archives of Photogrammetry and Remote Sensing, 33(B1; PART 1), 239-243.

Rahman, A., \& Cho, B.-K. (2016). Assessment of seed quality using non-destructive measurement techniques: A review. Seed Science Research, 26(4), 285-305.

Rogalski, A. (2003). Infrared detectors: status and trends. Progress in quantum electronics, 27(2-3), 59210.

Roy, S. D., Das, D. H., Bhowmik, M. K., \& Ghosh, A. K. (2016). Bruise detection in apples using infrared imaging. In: The 9th International Conference on Electrical and Computer Engineering (ICECE) (pp. 118-122). Dhaka, Bangladesh: IEEE.

Shepard, S. M., Ahmed, T., \& Lhota, J. R. (2004). Experimental considerations in vibrothermography. In: Thermosense XXVI, vol. 5405 (pp. 332-335): International Society for Optics and Photonics.

Theodorakeas, P., Cheilakou, E., Ftikou, E., \& Koui, M. (2015). Passive and active infrared thermography: an overview of applications for the inspection of mosaic structures. In: Journal of Physics: Conference Series, vol. 655 (p. 012061): IOP Publishing.

Tsakanikas, P., Pavlidis, D., \& Nychas, G.-J. (2015). High throughput multispectral image processing with applications in food science. PLOS One, 10(10), e0140122. 
Vadivambal, R., Chelladurai, V., Jayas, D., \& White, N. D. (2011a). Determination of sprout-damaged barley using thermal imaging. Agricultural Engineering International: CIGR Journal, 13(2), 16.

Vadivambal, R., Chelladurai, V., Jayas, D. S., \& White, N. D. (2010). Detection of sprout-damaged wheat using thermal imaging. Applied Engineering in Agriculture, 26(6), 999-1004.

Vadivambal, R., \& Jayas, D. S. (2011b). Applications of thermal imaging in agriculture and food industry - a review. Food and bioprocess technology, 4(2), 186-199.

Varith, J., Hyde, G. M., Baritelle, A. L., Fellman, J. K., \& Sattabongkot, T. (2003). Non-contact bruise detection in apples by thermal imaging. Innovative Food Science \& Emerging Technologies, 4(2), 211-218.

Veena, T., Arlene Christina, G. D., \& Bided, C. (2015). Insect detection methods. National Academy of Agricultural Science (NAAS), 33(3), 979-985.

Villaseñor-Mora, C., Martínez-Torres, P., Gonzalez-Vega, A., Borjas-García, S. E., Espinosa, G., \& Hernandez, V. H. (2017). Correlation of post-harvest avocado ripening process with the thermal emissivity measured from the peel. Applied Engineering in Agriculture, 33(2), 267-272.

Vollmer, M., \& Möllmann, K.-P. (2017). Infrared thermal imaging: fundamentals, research and applications. $2^{\text {nd }}$ Edition, Wiley-VCH VerlagGmbH \& Co.KGaA, Boschstr. 12, 69469 Weinheim, Germany.

Zhang, T., Wei, W., Zhao, B., Wang, R., Li, M., Yang, L., Wang, J., \& Sun, Q. (2018). A reliable methodology for determining seed viability by using hyperspectral data from two sides of wheat seeds. Sensors, 18(3), 813.

Zhang, X., \& Brusewitz, G. (1990). Corn moisture measurement by infrared thermometry. Transactions of the ASAE, 33(2), 553-0558.

Zhang, X., Liu, F., He, Y., \& Li, X. (2012). Application of hyperspectral imaging and chemometric calibrations for variety discrimination of maize seeds. Sensors, 12(12), 17234-17246. 
Table 1 Applications of thermal imaging technique in different scenarios of seed quality evaluation

\begin{tabular}{|c|c|c|c|c|c|c|}
\hline Crop & Applications & $\begin{array}{l}\text { Thermal } \\
\text { Camera }\end{array}$ & $\begin{array}{c}\text { Spectral } \\
\text { range } \\
(\mu \mathrm{m})\end{array}$ & $\begin{array}{l}\text { Resolution } \\
\text { (pixels) }\end{array}$ & Data modeling & References \\
\hline Lettuce & Viability estimation & SC7600-FLIR & $1.5-5$ & $640 \times 512$ & $\begin{array}{l}\text { Emission signals were fitted with a two-term } \\
\text { exponential model }\end{array}$ & (Kim et al., 2013) \\
\hline Pepper & Viability estimation & SC7600-FLIR & $1.5-5$ & $640 \times 512$ & $\begin{array}{l}\text { Photothermal signals were regressed using a } \\
\text { two-term exponential decay model }\end{array}$ & (Kim et al., 2014) \\
\hline Pea & $\begin{array}{l}\text { estimation of viability \& } \\
\text { germination capacity }\end{array}$ & $\begin{array}{l}\text { AGEMA } 880 \\
\text { LWB }\end{array}$ & $8-13$ & - & - & (Baranowski et al., 2003) \\
\hline Pea & $\begin{array}{l}\text { Viability assessment and } \\
\text { seed classification }\end{array}$ & Ti55-Fluke & $8-14$ & $320 \times 240$ & $\begin{array}{l}\text { Support vector machine (SVM) for } \\
\text { classifying seeds to viability classes }\end{array}$ & (Men et al., 2017) \\
\hline $\begin{array}{l}\text { Garden pea, } \\
\text { Wheat and Rape }\end{array}$ & $\begin{array}{l}\text { Prediction of seed } \\
\text { viability }\end{array}$ & $\begin{array}{l}\text { ThermaCAM TM } \\
\text { SC3000-FLIR }\end{array}$ & $8-9$ & $320 \times 240$ & $\begin{array}{l}\text { Monte Carlo simulation to predict thermal } \\
\text { profiles and seed viability }\end{array}$ & (Kranner et al., 2010) \\
\hline Norway spruce & $\begin{array}{l}\text { Identification of viable, } \\
\text { empty and infested } \\
\text { seeds }\end{array}$ & SC7000-FLIR & $1.5-5.1$ & $640 \times 512$ & $\begin{array}{l}\text { Support Vector Machine }(\mathrm{SVM}) \text { and } \\
\text { Sparse logistic regression }\end{array}$ & (Dumont et al., 2015) \\
\hline Wheat & Detect insect infestation & $\begin{array}{l}\text { ThermaCAM TM } \\
\text { SC500-FLIR }\end{array}$ & $7.5-13$ & $320 \times 240$ & $\begin{array}{l}\text { Linear discriminant analysis (LDA) \& } \\
\text { Quadratic discriminant analysis (QDA) }\end{array}$ & $\begin{array}{l}\text { (Manickavasagan et al., } \\
\text { 2008) }\end{array}$ \\
\hline
\end{tabular}




\begin{tabular}{|c|c|c|c|c|c|c|}
\hline Crop & Applications & $\begin{array}{l}\text { Thermal } \\
\text { Camera }\end{array}$ & $\begin{array}{c}\text { Spectral } \\
\text { range } \\
(\mu \mathrm{m})\end{array}$ & $\begin{array}{l}\text { Resolution } \\
\text { (pixels) }\end{array}$ & Data modeling & References \\
\hline Wheat & $\begin{array}{c}\text { Detection of fungal } \\
\text { infection by Aspergillus } \\
\text { Spp and Penicillium spp. }\end{array}$ & $\begin{array}{l}\text { ThermaCAM TM } \\
\text { SC500 of FLIR }\end{array}$ & $7.5-13$ & $320 \times 240$ & $\begin{array}{l}\text { Linear discriminant analysis (LDA) \& } \\
\text { Quadratic discriminant analysis (QDA) }\end{array}$ & (Chelladurai et al., 2010) \\
\hline Wheat & Class identification & $\begin{array}{l}\text { ThermaCAM TM } \\
\text { SC500-FLIR }\end{array}$ & $7.5-13$ & $320 \times 240$ & Quadratic discriminant analysis (QDA) & $\begin{array}{l}\text { (Manickavasagan et al., } \\
\text { 2010) }\end{array}$ \\
\hline Wheat \& Barley & $\begin{array}{l}\text { Detection of sprout } \\
\text { damages }\end{array}$ & $\begin{array}{l}\text { ThermaCAM TM } \\
\text { SC500-FLIR }\end{array}$ & $7.5-13$ & $320 \times 240$ & $\begin{array}{l}\text { Linear discriminant analysis (LDA) \& } \\
\text { Quadratic discriminant analysis (QDA) }\end{array}$ & $\begin{array}{l}\text { (Vadivambal et al., 2011a; } \\
\text { Vadivambal et al., 2010) }\end{array}$ \\
\hline $\begin{array}{l}\text { Wheat, Barely \& } \\
\text { Canola }\end{array}$ & Heating non-uniformity & $\begin{array}{l}\text { ThermaCAM TM } \\
\text { SC500-FLIR }\end{array}$ & $7.5-13$ & $320 \times 240$ & $\begin{array}{l}\text { General linear model; Analysis of variance } \\
\text { (ANOVA) }\end{array}$ & (Manickavasagan, 2007) \\
\hline Paddy & Detection of husks & E60-FLIR & $7.5-13$ & $320 \times 240$ & Simple image thresholding & $\begin{array}{l}\text { (Jamil \& Khairunniza- } \\
\text { Bejo, 2014) }\end{array}$ \\
\hline Paddy & $\begin{array}{l}\text { Prediction of moisture } \\
\text { content, maturity and } \\
\text { foreign materials }\end{array}$ & E60-FLIR & $7.5-13$ & $320 \times 240$ & Pearson's correlation analysis & $\begin{array}{l}\text { (Khairunniza-Bejo et al., } \\
\text { 2016) }\end{array}$ \\
\hline Paddy & $\begin{array}{l}\text { Detection of fungal } \\
\text { infection }\end{array}$ & E60-FLIR & $7.5-13$ & $320 \times 240$ & Simple visual comparison & $\begin{array}{l}\text { (Khairunniza-Bejo et al., } \\
\text { 2013) }\end{array}$ \\
\hline Mung bean & $\begin{array}{l}\text { Detecting the stages of } \\
\text { C. maculatus infestation }\end{array}$ & $\begin{array}{l}\text { ThermaCAM TM } \\
\text { SC500-FLIR }\end{array}$ & $7.5-13$ & $320 \times 240$ & $\begin{array}{l}\text { Linear discriminant analysis (LDA) \& } \\
\text { Quadratic discriminant analysis (QDA) }\end{array}$ & (Chelladurai et al., 2012) \\
\hline Pistachio & $\begin{array}{l}\text { Detection of fungal- } \\
\text { infected kernels }\end{array}$ & $\begin{array}{l}\text { ULIRvision- } \\
\text { TI160 }\end{array}$ & $8-14$ & $160 \times 120$ & $\begin{array}{c}\text { Threshold based classification (TBC) } \\
\text { algorithm }\end{array}$ & (Kheiralipour et al., 2013) \\
\hline
\end{tabular}




\section{Figure captions}

Figure 1 Electromagnetic spectrum with visible $(380-740 \mathrm{~nm})$ and infrared $(0.74-1000 \mu \mathrm{m})$ spectra magnified.

Figure 2 Typical components of a thermal imaging system used in seed quality assessment. A thermal excitation unit was provided in case of active thermal imaging system.

Figure 3 Operational principles of image formation using (a) line-scanning mode (a) and staring mode supported with focal plan array (FPA) detector.

Figure 4 Different practical applications of thermal imaging in agriculture, food and seed sectors.

Figure 5 Thermal decay amplitude images (a) and thermal decay delay-time images (b) of representative healthy seed and seeds aged for 24,48 , and $72 \mathrm{~h}$ produced using an exponential decay model (Kim et al., 2013).

Figure 6 Thermal images demonstrating that the sprout-damaged kernel (a) exhibits higher temperature than the healthy kernel (b) as indicated in the temperature color bar (adapted from Vadivambal et al., 2010).

Figure 7 Input thermal images of paddy seeds containing different amounts of husk (a) and binary images resulting after a simple thresholding to detect husk (white pixels) presented in the images (b). In all thermal images, paddy husks are consistently darker than paddy seeds because they have lower thermal conductivity and lower temperature compared to paddy seeds (adapted from Jamil \& Khairunniza-Bejo, 2014). 


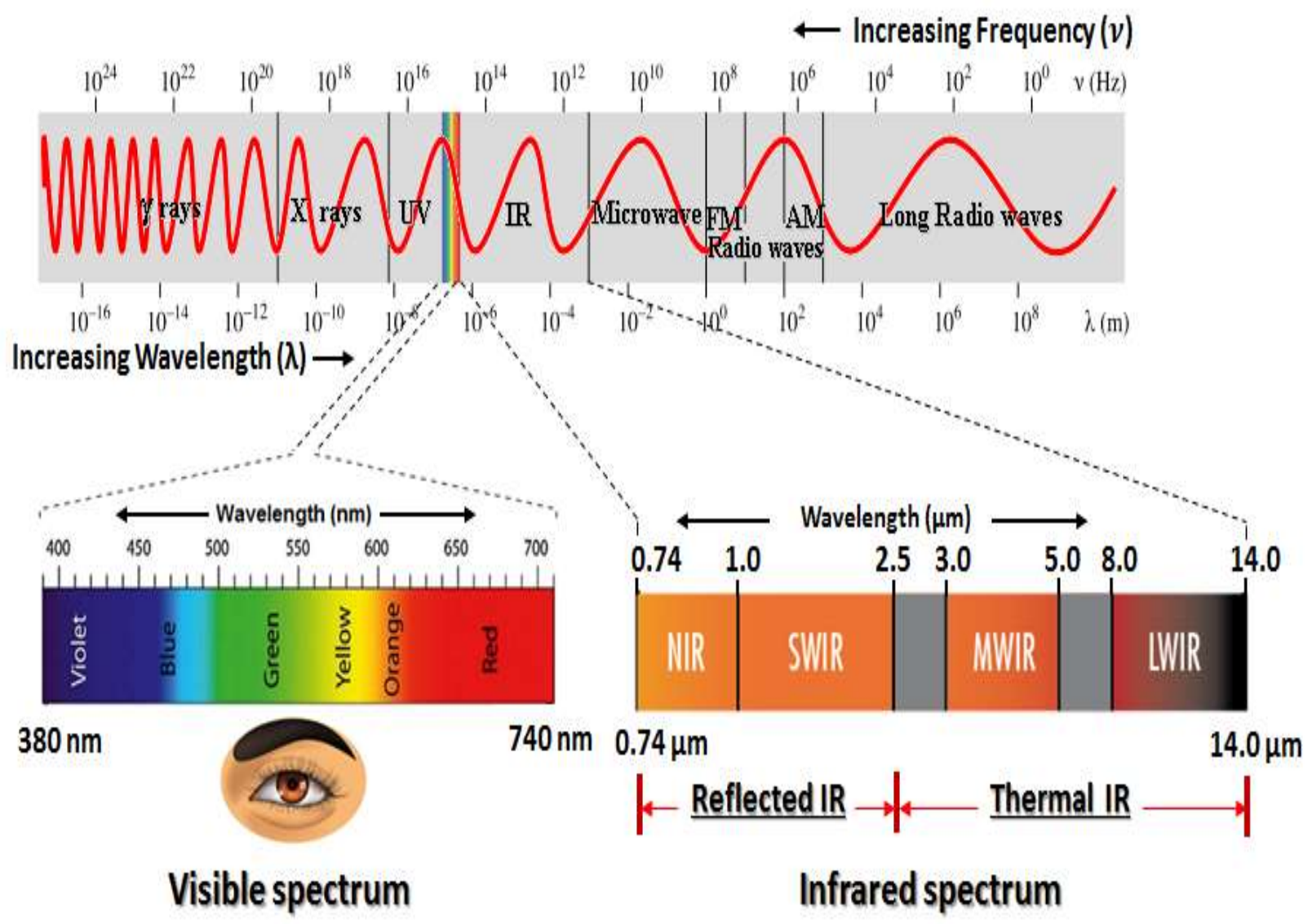

Figure 1 


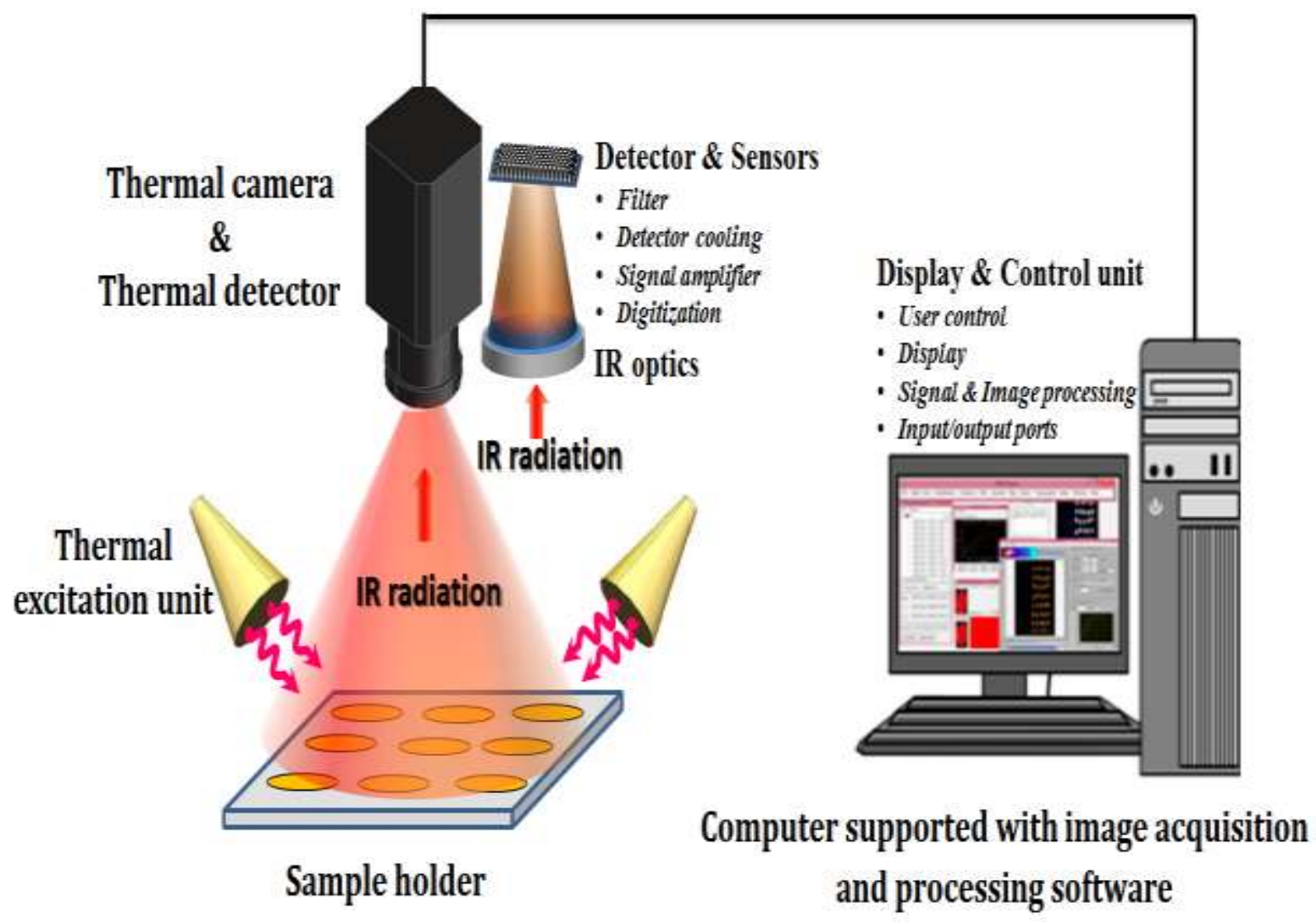

Figure 2 


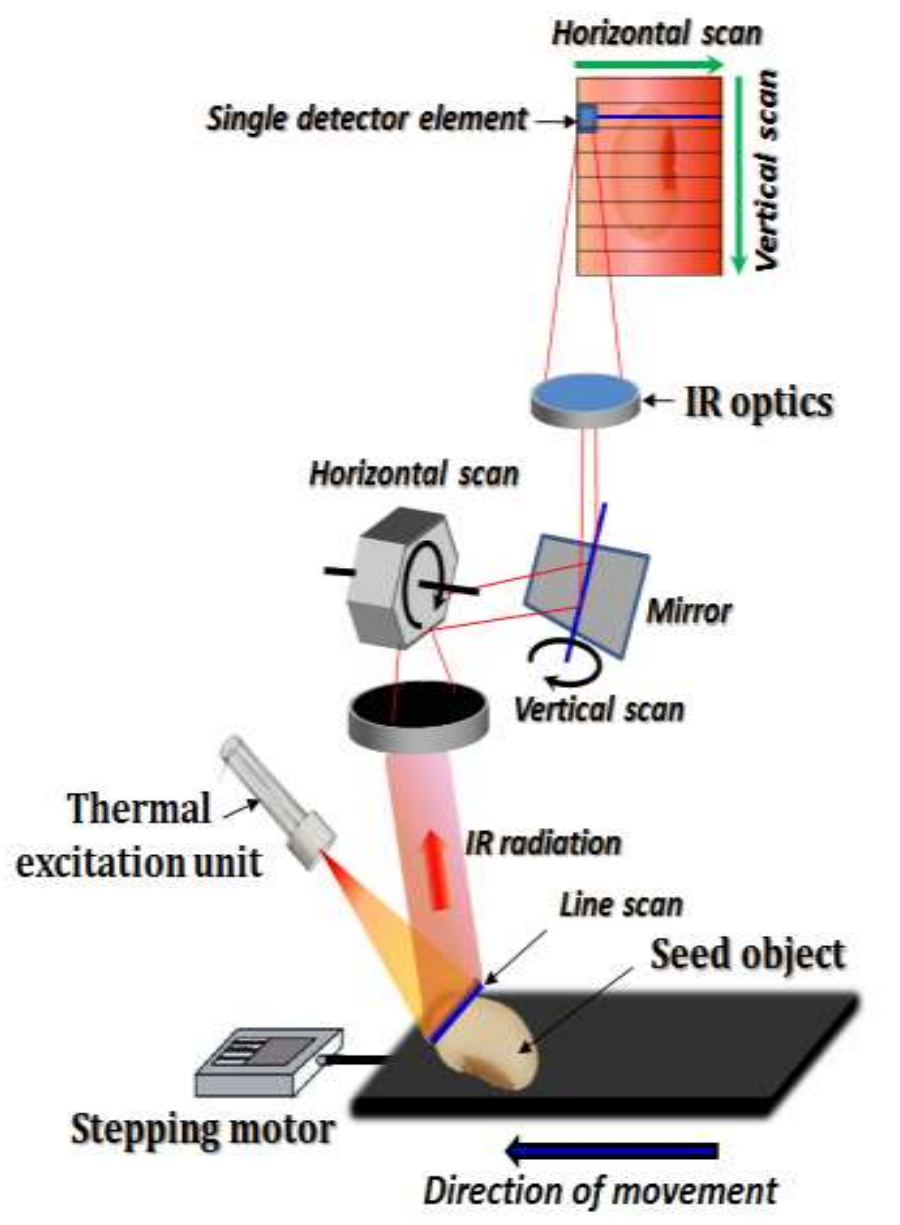

(a) Scanning mode

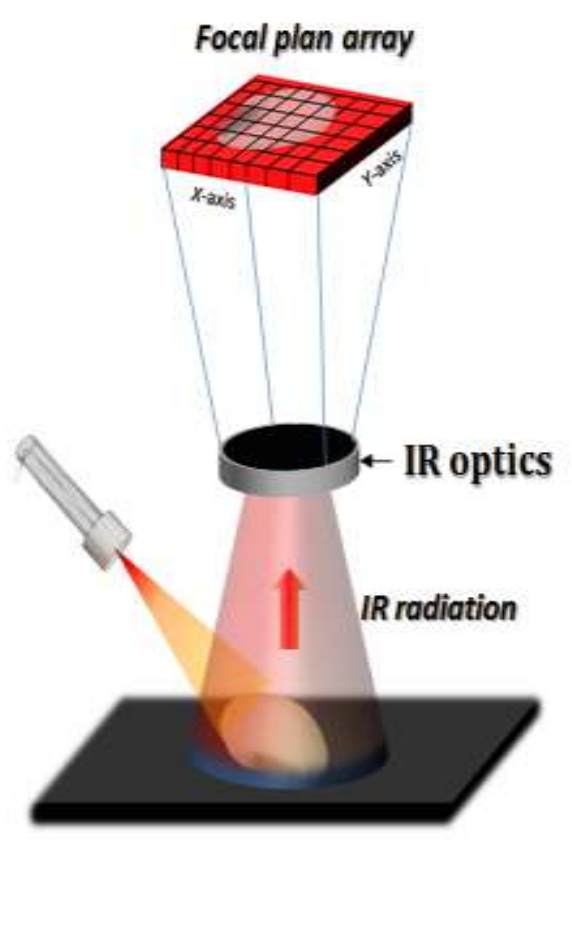

(b) Staring mode

Figure 3 


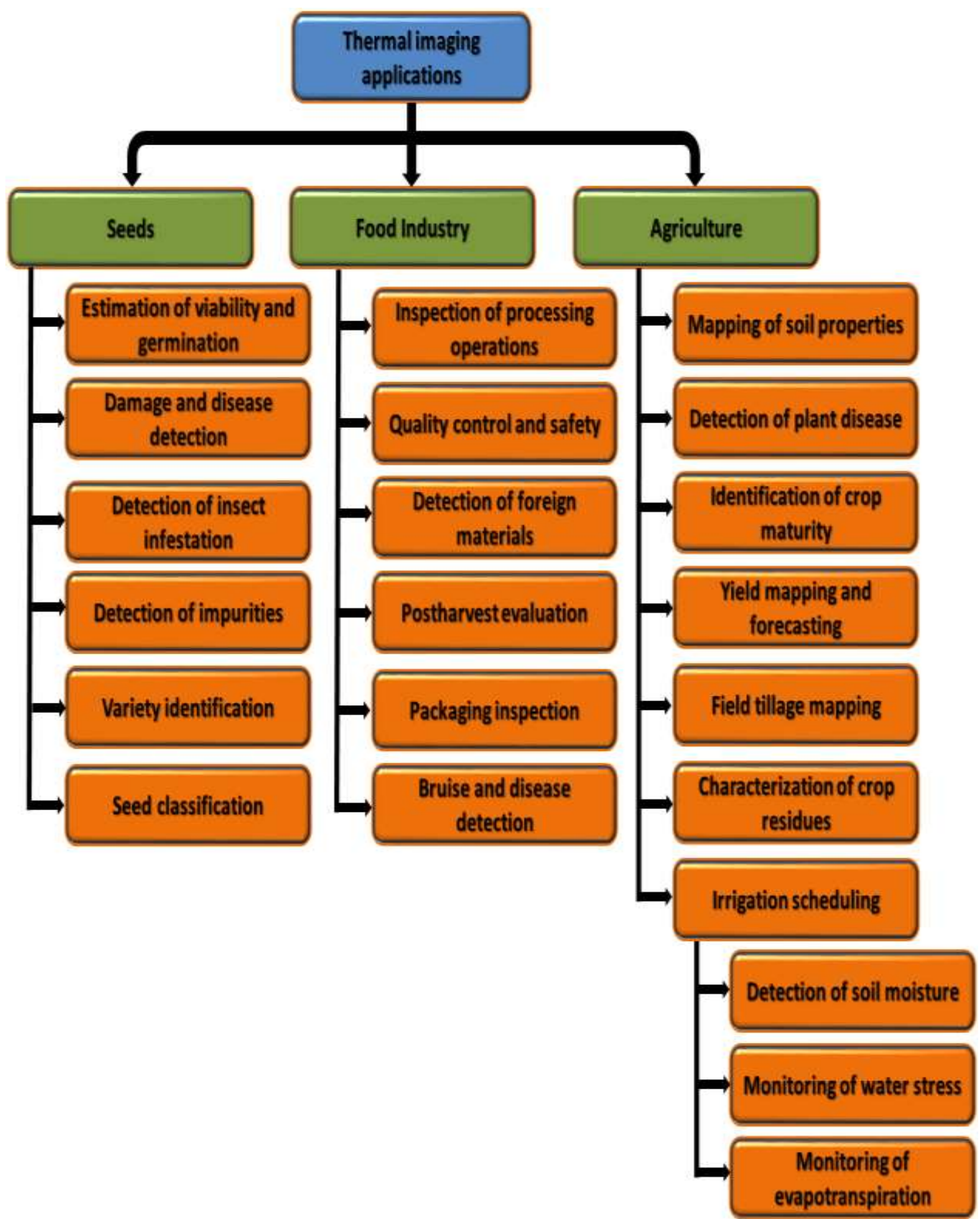

Figure 4 

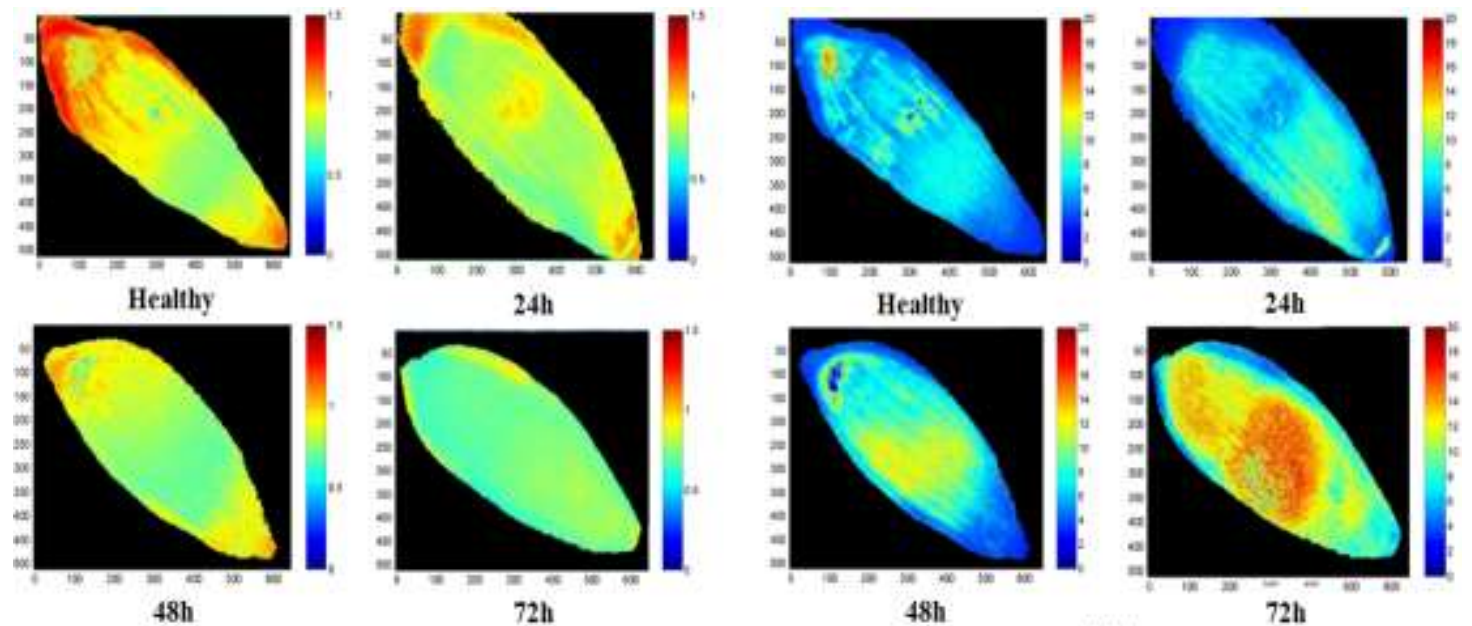

(a)

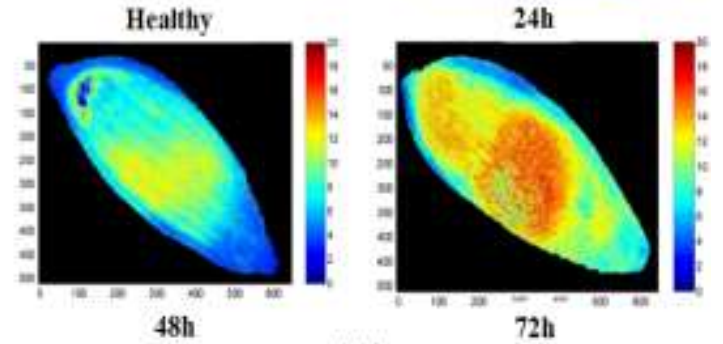

(b)

Figure 5 

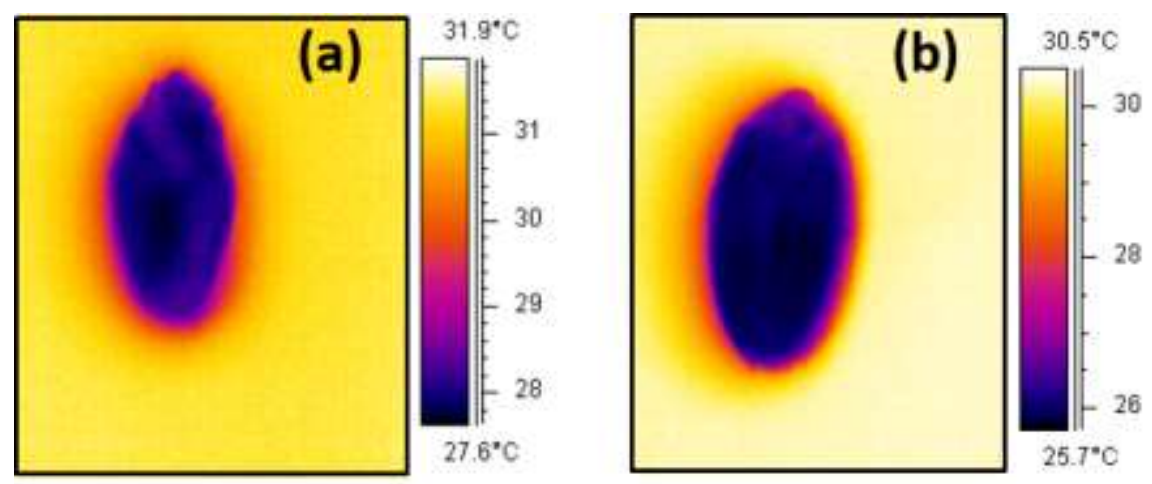

Figure 6 

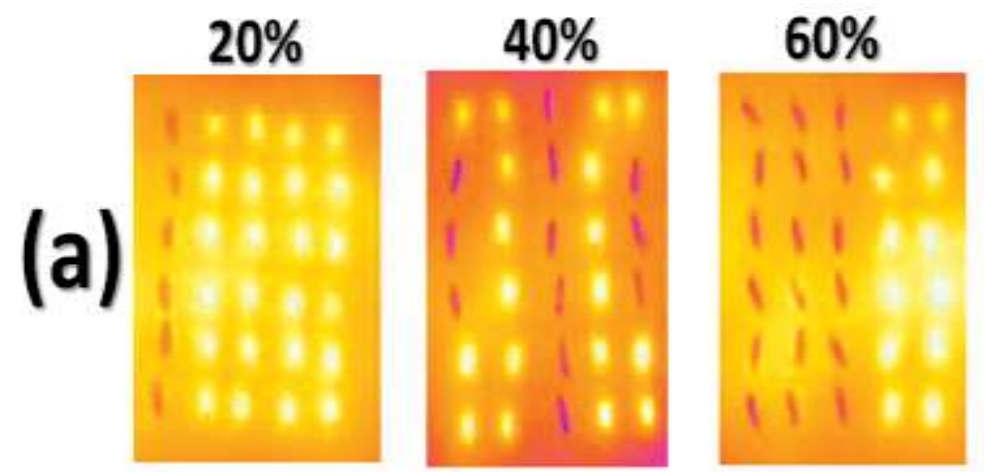

100\% Husk $100 \%$ Paddy
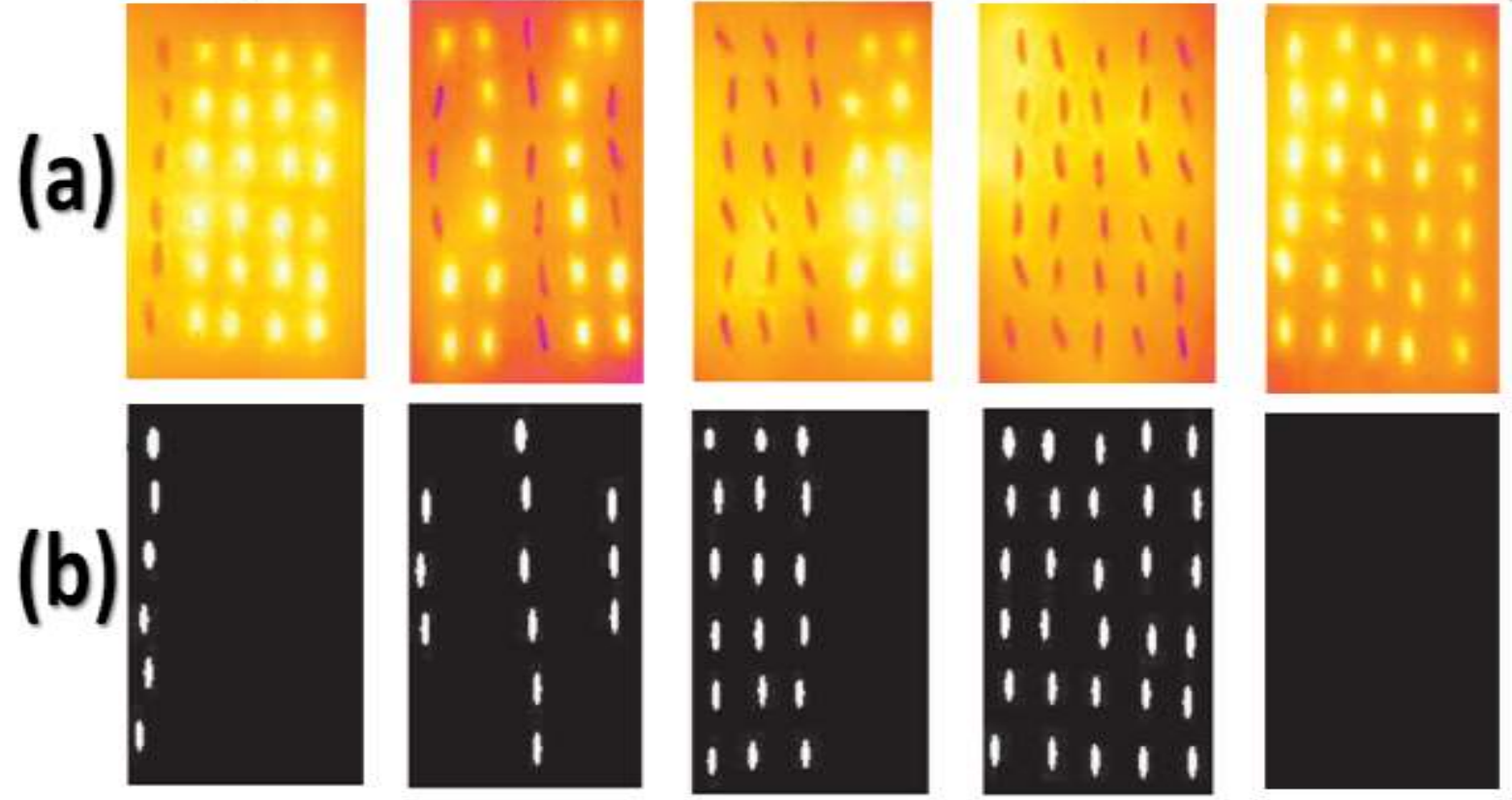

$\begin{array}{lllll}1 & 1 & 1 & 1 & 1 \\ 1 & 1 & 1 & 1 & 1 \\ 1 & 1 & 1 & 1 & 1 \\ 1 & 1 & 1 & 1 & 1 \\ 1 & 1 & 1 & 1 & 1 \\ 1 & 1 & 1 & 1 & 1\end{array}$

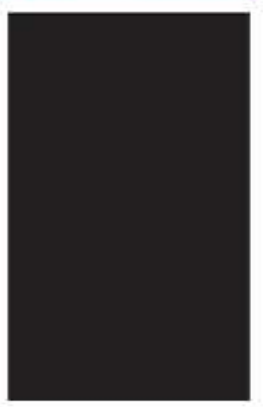

Figure 7 